Supporting information for:

\title{
Air Pollutant Emissions Induced by Population Migration in China
}

Guang Shi ${ }^{1}, X i$ Lu $^{1,2,3^{*}}$, Yu Deng ${ }^{4}$, Johannes Urpelainen ${ }^{5}$, Lan-Cui Liu' ${ }^{6}$, Zhonghua

Zhang ${ }^{1}$, Wendong Wei $^{7}$, Haikun Wang ${ }^{8}$

${ }^{1}$ School of Environment, Tsinghua University, Beijing 100084, P.R. China

${ }^{2}$ State Key Joint Laboratory of Environment Simulation and Pollution Control, Tsinghua University, Beijing 10084, P.R. China

${ }^{3}$ State Environmental Protection Key Laboratory of Sources and Control of Air Pollution Complex, Beijing 100084, China

${ }^{4}$ Institute of Geographic Sciences and Natural Resources Research, Chinese Academy of Sciences, Beijing 100101, P.R. China

${ }^{5}$ School of Advanced International Studies, Johns Hopkins University, Washington, DC 20036, USA.

${ }^{6}$ Business School, Beijing Normal University, Beijing 100875, P.R. China

${ }^{7}$ School of International and Public Affairs, Shanghai Jiao Tong University, Shanghai 200030, P.R. China

${ }^{8}$ State Key Laboratory of Pollution Control and Resource Reuse, School of the Environment, Nanjing University, Nanjing 210023, P.R. China

${ }^{*}$ Corresponding author: E-mail: xilu@tsinghua.edu.cn; Tel: 86-10-62781331

Number of pages: 53

Number of figures: 15

Number of tables: 10 


\section{Contents}

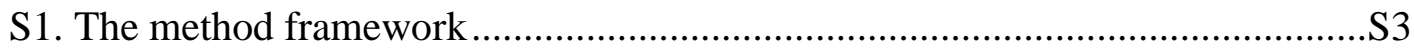

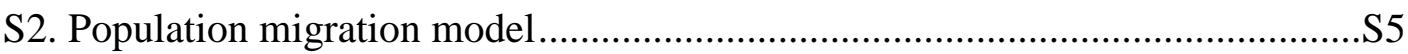

S3. Mapping emission inventory to input-output table ............................................

S4. Evaluation of indirect emissions embodied in consumption and investment with

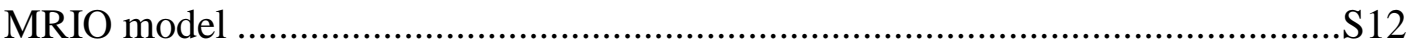

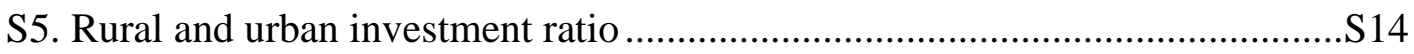

S6. Per-capita direct emissions of $\mathrm{NO}_{\mathrm{x}}, \mathrm{SO}_{2}$ and primary $\mathrm{PM}_{2.5}$ for rural and urban households

S7. Per-capita indirect $\mathrm{NO}_{\mathrm{x}}, \mathrm{SO}_{2}$ and primary $\mathrm{PM}_{2.5}$ emissions driven by consumption for rural and urban households

S8. Per-capita indirect $\mathrm{NO}_{x}, \mathrm{SO}_{2}$ and primary $\mathrm{PM}_{2.5}$ emissions driven by investment for rural and urban residents S27

S9. Changes in provincial consumption-based $\mathrm{NO}_{\mathrm{x}}, \mathrm{SO}_{2}$, primary $\mathrm{PM}_{2.5}$ emissions induced by migration.

S10. Uncertainty analysis S42

S10.1 Influences of Hukou migration S42

S10.2 Monte Carlo simulation S47

References S51 


\section{S1. The method framework}

As illustrated in Figure S1, the integrated approach adopted in this analysis combines three interlinked parts: a population migration model, a multiregional inputoutput (MRIO) model and an impact assessment model.

First, the population migration model combined with census data from China's National Bureau Statistics (NBS) is utilized to evaluate the population migration along four paths, namely intra-provincial rural to urban (RU), intra-provincial urban to urban (UU), inter-provincial RU and inter-provincial UU. Building on this, migration matrices are formed among 30 Chinese provinces (excluding Tibet, Hong Kong, Taiwan and Macao).

Second, using the MRIO model combined with emission inventory database developed by Tsinghua University ${ }^{1,2}$, we attribute the emissions of three criteria air pollutants including $\mathrm{NO}_{\mathrm{x}}, \mathrm{SO}_{2}$ and primary $\mathrm{PM}_{2.5}$ in China in 2012 to rural and urban consumption and investment. The total emissions evaluated here contain two parts: (1) the emissions driven by household consumption, which can be further divided into direct ones caused by residential energy consumption and indirect ones embodied in other product consumption; (2) the emissions driven by investment, which only contains indirect emission. Direct consumption emissions are associated with household primary energy use to satisfy the demand for space heating, cooking \& hot water and transport. In contrast, indirect emissions embodied in household consumption refers to pollutants emitted during the production and supply of goods and service 
which are finally consumed by households. Apart from this, investment-driven emissions refers to those embodied in rural and urban investment, which is also indirect emissions from the perspective of households.

Finally, based on the two models above, we evaluate the impacts of migration on emissions of air pollutants against a hypothetical scenario in which all migrants are assumed to return to their locations of household registration. The method framework is illustrated in Figure S1.

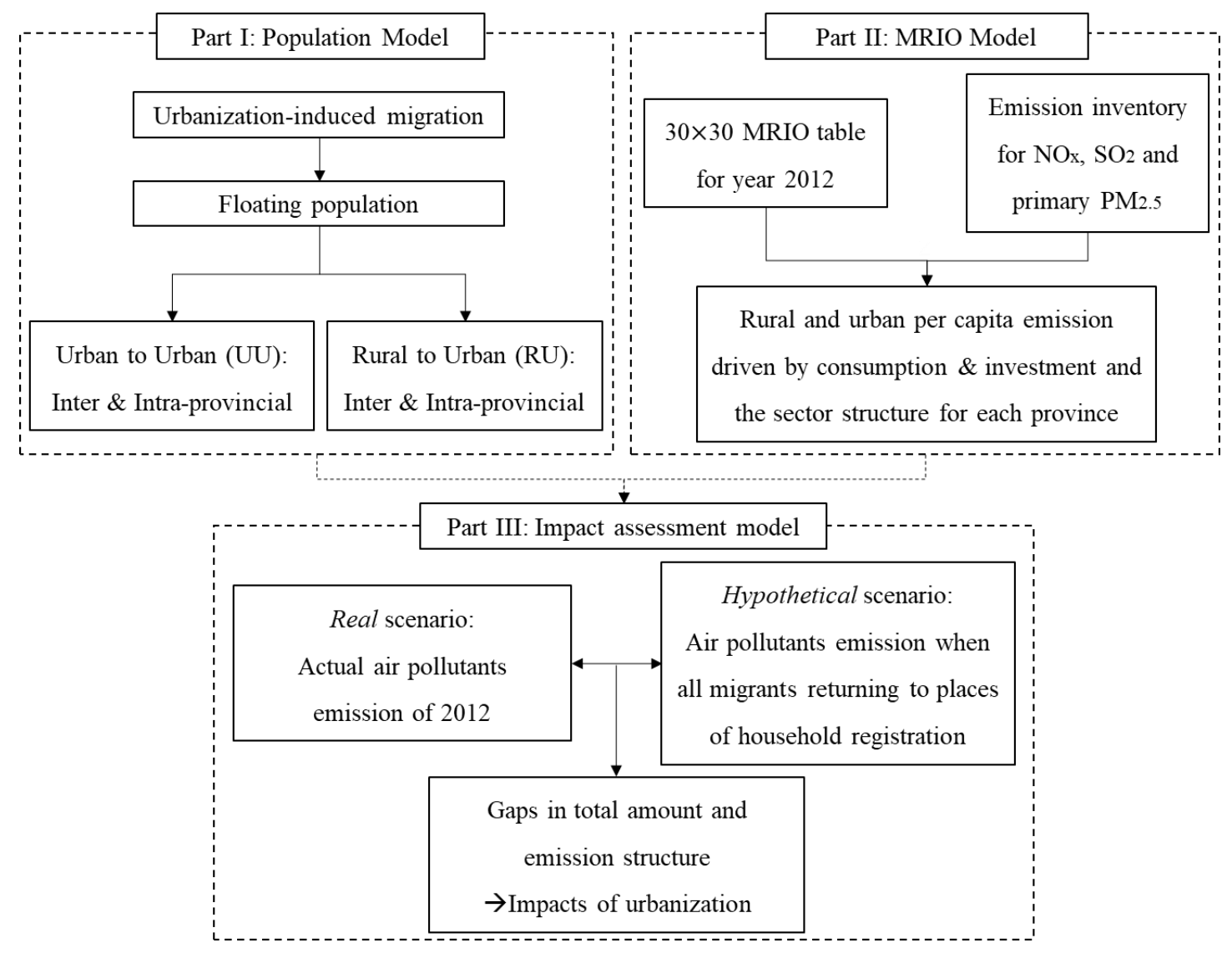

Figure S1. Method framework of this study. 


\section{S2. Population migration model}

Floating population, defined as individuals living in places other than their household registration areas for at least six months ${ }^{3,4}$, is used to represent the migrants in this analysis. In China's household registration (or Hukou) system, population fall into three categories: (a) temporary residents residing in places different from Hukou location for less than six months; (b) floating population and (c) population with current residence consistent with Hukou location ${ }^{4}$. Floating population dominate the population migration in China, and their residence time longer than six months allows for changes of lifestyle and poses tangible influences on associated air-pollutant emissions. Relevant data for floating population is obtained from the 2010 Chinese Census (the sixth national population census of the People's Republic of China) ${ }^{5}$ and the $1 \%$ National Population Sample Survey $2015^{6}$. We reorganize the different types of Hukou in the census as rural or urban population following the method below:

$$
\begin{aligned}
& \text { Rural registration }=\text { township }+ \text { village committee of town } \\
& \text { Urban registration }=\text { resident committee of town }+ \text { sub-district }
\end{aligned}
$$

If the floating population have rural registration, then they are considered moving out of rural areas, and if they have urban registration, they are moving out of urban areas. Theoretically, migration has four directions: UU, RU, urban to rural, and rural to rural. As the scale of the last two paths is relatively small in China, they are thus neglected in this study. 
The 2010 Chinese Census classifies the places of destination into rural or urban and collects data for each migration path. However, the $1 \%$ National Population Sample Survey 2015 does not distinguish the type for places of destination as rural or urban. So we first calculate the percentage of RU migrants in the total rural emigrants, as well as the percentage of UU migrants in the total urban emigrants, for each provincial migrating path $(30 \times 30$, without Tibet, Hong Kong, Macao and Taiwan) in 2010 to get the migration structure. Then based on the migration structure of 2010 , we allocate the rural and urban emigrants among provinces in 2015 and obtain the amount of RU and UU migrants. In this way we establish the $30 \times 30$ matrices of RU and UU migration on the provincial level in China for the year of 2010 and 2015. Finally, a linear interpolation method is used to get results for 2012, as is shown in Figures S2 and S3. It should be noticed that the data used here represent the accumulative floating population in 2012 .

In 2012, there are 106.5 million UU migrants, with $78.2 \%$ of them moving inside the same province and $21.7 \%$ migrating cross provincial borders. As is shown in Figure $\mathrm{S} 2$, for some more developed provinces and municipalities (the main destinations for migrants), such as Guangdong, Beijing, Shanghai, there are more inter-provincial UU immigrants than other provinces. There are 124.6 million RU migrants, and $59.6 \%$ of them migrate inside the same province while the others are inter-provincial migrants. Compared to UU migration, there is a higher percentage of inter-provincial migrants for RU. For the provinces of Guangdong, Zhejiang, Jiangsu and Xinjiang and municipalities of Shanghai, Beijing and Tianjin, the inter-provincial RU migrants 
moving-in are more than the ones migrating within the same province from rural to urban areas. On the opposite, for the provinces of Anhui, Jiangxi, Hunan, Henan, Guangxi, Guizhou, Hubei and Sichuan, the amount of inter-provincial RU migrants moving-out is larger than that of migrants within the province. As is shown in Figures S2 and S3, Guangdong, Shanghai, Zhejiang, Beijing and Jiangsu are the main places of destination for migrants, with $19.3,7.6,7.1,5.8$ and 2.8 million population moving in respectively. While Anhui, Henan, Hunan, Sichuan and Jiangxi are the major provinces with population outflow, with the values of $-7.1,-6.5,-5.9,-5.8$ and -4.5 million respectively.

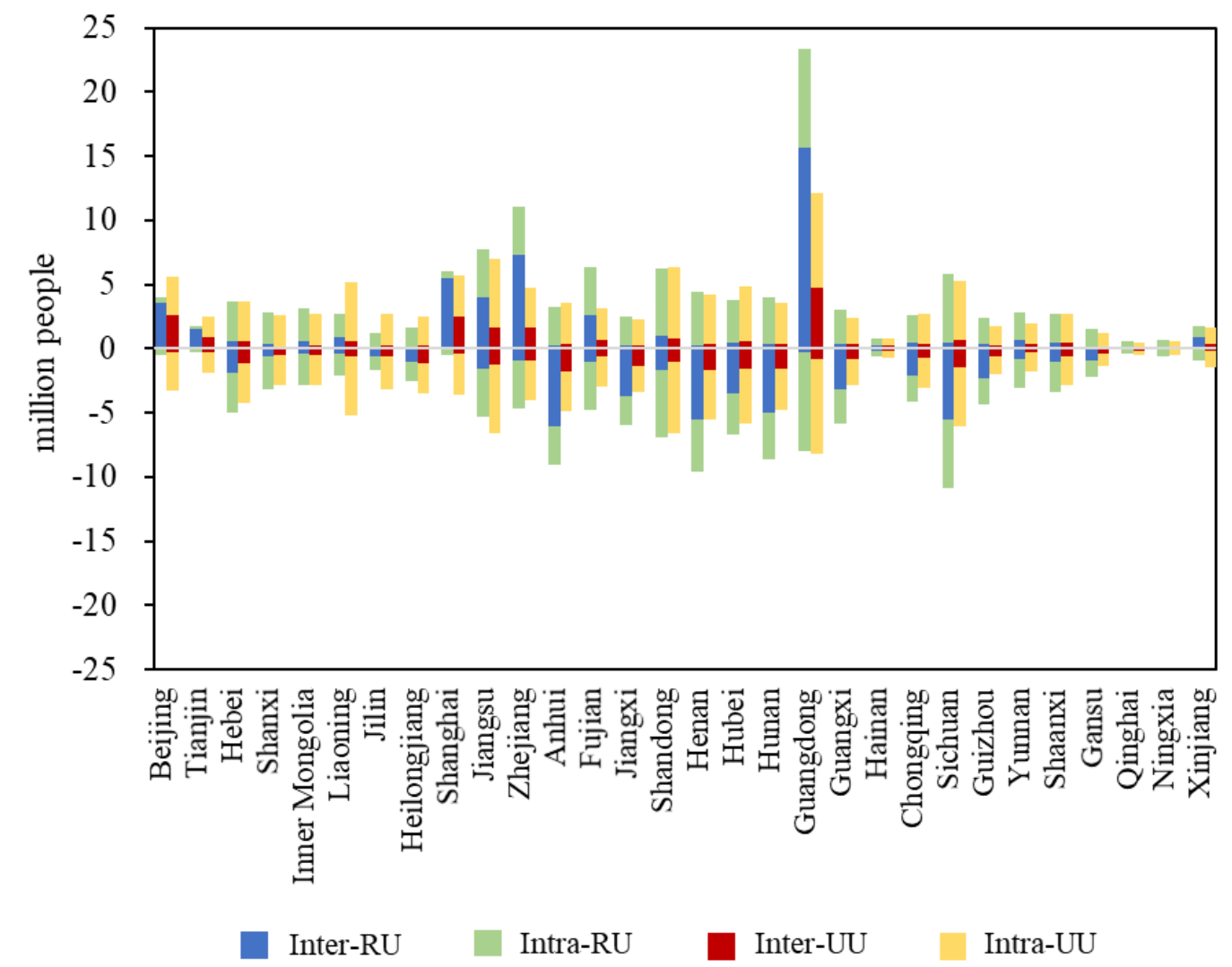

Figure S2. The population migration of each province in 2012. The migration includes four paths: Inter-provincial RU, Intra-provincial RU, Inter-provincial UU and Intra-provincial UU, with 
positive values indicating inward migration and negative values indicating outward one. No data for Tibet, Hong Kong, Macao and Taiwan.

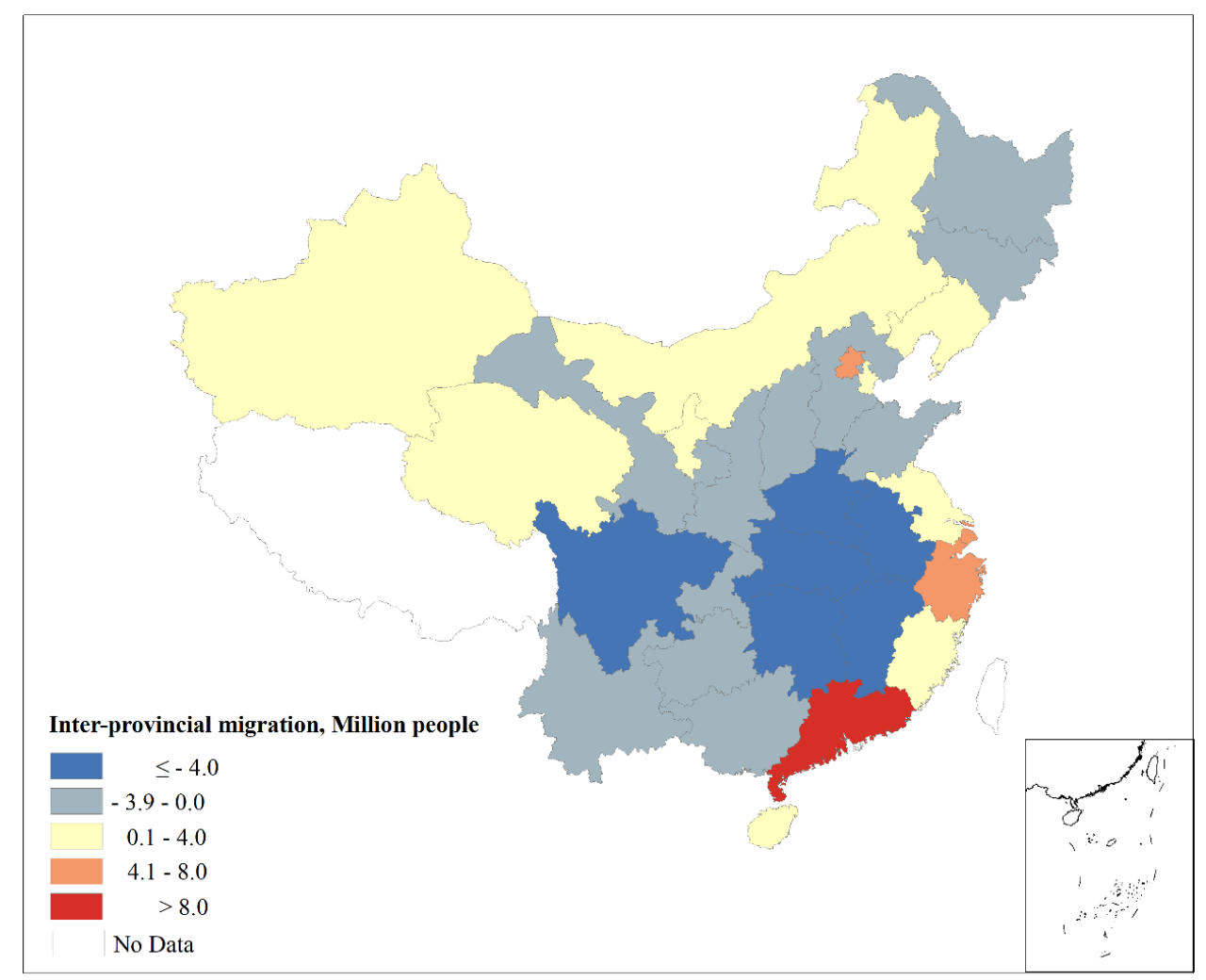

Figure S3. The net inter-provincial population migration in 2012, including RU and UU paths. No data for Tibet, Hong Kong, Macao and Taiwan.

\section{S3. Mapping emission inventory to input-output table}

Figure S4 illustrates the method of mapping the emission inventory to the multiregional input-output (MRIO) table. We first reorganize the 30 sectors in the MRIO table ${ }^{7}$ into 26 sectors by aggregating the Wholesale and retailing, Hotel and restaurant, Leasing and commercial services, Scientific research and Other services sectors (numbered from 26 to 30 in the original MRIO table) into a new Other services sector, with the rest 25 sectors unchanged. Then these 26 sectors are further classified into 6 categories, namely Agriculture, Light industry, Heavy industry, Utility industry, 
Construction and Services (see Figure 4), for the sake of clarity of analysis and demonstration. The Heavy industry category actually includes 15 sectors (numbered from 2 to 5 and from 11 to 21 in the MRIO table), which covers mining, equipment manufacture, metal and nonmetal processing industries, etc.

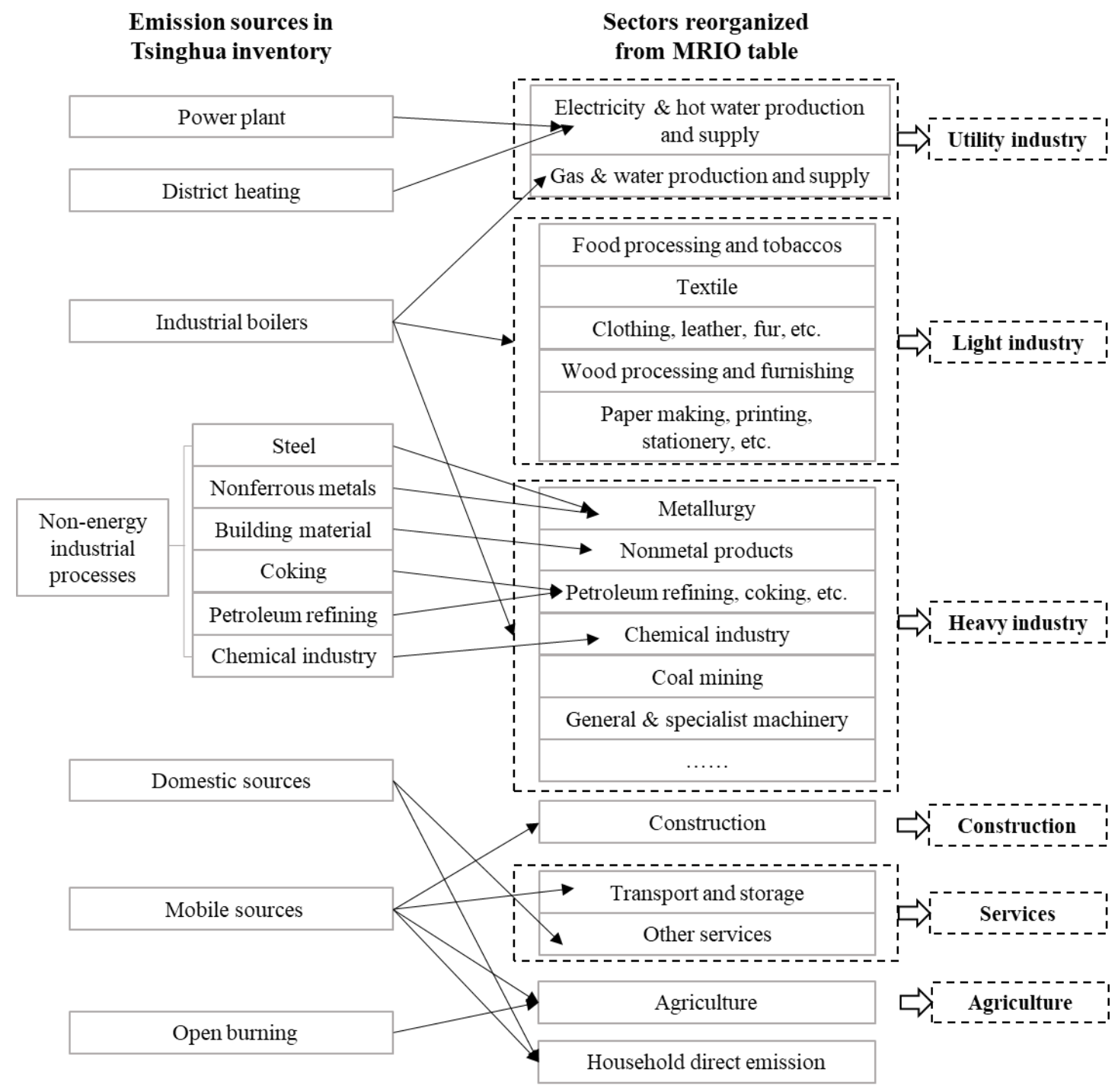

Figure S4. The mapping between Tsinghua emission inventory and MRIO table. The dashed boxes show how the sectors are allocated to the 6 categories. The Heavy industry category covers the following 15 sectors: Coal mining; Petroleum and gas; Metal mining; Nonmetal mining; Petroleum refining, coking, etc.; Chemical industry; Nonmetal products; Metallurgy; Metal products; General and specialist machinery; Transport equipment; Electrical equipment; Electronic equipment; 
Instrument and meter; and Other manufacturing. The Household direct emission is a separate category which actually has no relationship with MRIO table.

The emission inventory adopted here is developed by Tsinghua University, which is based on the activity data (such as industrial products, energy consumption, and solvent use), technology-based uncontrolled emission factors and penetrations of pollution-control technologies ${ }^{1,2}$. The emission sources are classified according to the technologies adopted and services provided, including Power plant, District heating, Industrial boilers, various Non-energy industrial processes, Domestic sources, Mobile sources and Open burning. Emissions from some of these unit/technology-based sources can be allocated to the economic sectors in MRIO table directly, for example the power plant and those non-energy industrial processes (see Figure S4). While for those aggregate sources, such as industrial boilers and cars, extra data are required for mapping.

We use the sectoral energy consumption data of each province for the year of 2012 as assistance to allocate the emissions from Industrial boilers to corresponding sectors, including those belonging to Light and Heavy industry category as well as the Gas \& water production and supply sector (see Figure S4). The energy consumption data are obtained from Shan et al. ${ }^{8}$, the China Emission Accounts \& Datasets database $(C E A D s)^{9}$. The data are measured in different physical units (e.g. tonne, cubic meter), and to facilitate calculation the physical units are converted to coal equivalent. The conversion factors from physical units to coal equivalent are from China Energy Statistical Yearbook ${ }^{10}$. 
Extra steps are also taken to allocate the emissions from cars. According to the different types of possession and usage, cars can be classified into two categories: commercial cars and private cars. Commercial cars refer to those owned by organizations or companies and are used to earn profits. They are part of the Transport and Storage sector. While private cars are owned by households, and the emissions associated with them belong to the household direct emissions. Thus, the emissions from cars are first divided into Transport and Storage sector and household direct consumption based on the proportion of commercial and private cars, with the data from China's Auto Market Almanac ${ }^{11}$. Then the emission associated with private cars are divided into rural and urban parts according to rural and urban household petroleum and diesel consumption obtained from CEADs.

The emission inventory evaluates the direct emissions of rural and urban households separately, including the cooking and space heating events, with the differences resulted from the type, structure and amount of energy consumed. In addition, the direct emissions from household private transportation have been divided into rural and urban with the methods introduced above, in order to embrace the rural and urban differences.

It should be noticed that in this study Construction sector includes the process of building construction and decoration while excludes building material production which belongs to other sectors, such as Nonmetal products and Metal products. The inventory does not cover the information of fugitive dust emissions from the 
construction process, which might underestimate the emission of primary $\mathrm{PM}_{2.5}$ from construction sector. Furthermore, uncertainties may exist in the mapping process due to the different sector classification methods of the emission inventory and the MRIO table.

\section{S4. Evaluation of indirect emissions embodied in consumption and investment with MRIO model}

The direct emissions resulted from household energy use can be directly evaluated with the emission inventory database, while the indirect emissions embodied in other product and service consumption and investment need to be evaluated with environmentally extended MRIO model.

The indirect emissions can be evaluated by equation (1):

$$
E_{e m b}=\widehat{E F}(I-A)^{-1} Y
$$

where $E_{e m b}$ is the indirect emissions of the three criteria air pollutants (including $\mathrm{NO}_{\mathrm{x}}$, $\mathrm{SO}_{2}$, primary $\mathrm{PM}_{2.5}$ ) embodied in consumption and investment; $\widehat{E F}$ is a diagonal matrix with elements indicating the sectoral direct emission intensities; $I$ is an identity matrix; $A$ is the direct requirements matrix derived from the MRIO table; and $Y$ denotes the matrix of final demand. Further, $(I-A)^{-1}$ is defined as Leontief inverse matrix $(L)$, which depicts the total requirements to satisfy per-unit final demand $(Y)$. Here, $Y$ includes final demand for rural and urban consumption and investment, which are the columns of rural household consumption, urban household consumption and fixed 
capital formation in the MRIO table ${ }^{7}$

The emission factor $F$ is calculated with the following formulation:

$$
E F=E_{d i r} \hat{X}^{-1}
$$

where $E_{\text {dir }}$ is the direct emissions of each production sector obtained from the emission inventory, with the mapping processes introduced in Section $\mathrm{S} 3 ; X$ is the total output of each sector, obtained by summing up each row in the MRIO table, and $\hat{X}$ is its diagonal form.

$A$ is calculated with the following formulation:

$$
A=M \hat{X}^{-1}
$$

where $M$ is the inter-industry transaction matrix in the MRIO table, which depicts the economic interdependence among the production sectors. The $X$ here is actually the total input of each sector, obtained by summing up each column for each sector in the MRIO table. While in MRIO table, the total input of each sector should be equal to its total output, thus $X$ in equation (3) is actually same as that in equation (2).

Equation (1) essentially traces the indirect emissions 'from upstream to downstream' along the supply chain ${ }^{12}$. In other words, this method identifies the ultimate upstream sectors that actually emit those pollutants during production to fully satisfy demands for specific consumption or investment. Peters ${ }^{13}$ pointed out that this calculation method actually allocates the emissions driven by specific consumption 
demand to the 'producers' which emit the pollution and are mainly energy-intensive industries, such as electricity generation and supply sector.

The direct requirement coefficient matrix $A$ might be different for rural and urban consumption and investment. Ideally, two separate MRIO tables for rural and urban production may result more accurate quantification between the rural and urban differences. Given that the MRIO tables are not available for such differentiation, the present study characterizes the differences between rural and urban indirect emissions based on their scale and structure of consumption and investment.

\section{S5. Rural and urban investment ratio}

The original MRIO table has only the total amount of fixed capital formation of each province and does not distinguish between rural and urban investment. Here, we allocate the fixed capital formation to rural and urban population based on the rural and urban investment data from Statistical Yearbook of the Chinese Investment in Fixed Assets $^{14,15}$. Since 2011, the yearbook has only collected data of individual investments for rural investment, rather than the total amounts including both individual investments from households and collective investments from rural enterprises or organizations. As a result, the statistical data of 2012 undervalues the actual rural investment, leading to obvious bias. Thus we use the average investment of year 2009 and 2010 to represent the rural-urban ratio for year 2012.

Table S1 shows the percentage of rural investment in the total sum of both rural and urban investment for each province. In the yearbook, some industry sectors are 
merged into a larger category for the rural data: (1) The sectors of Coal mining, Petroleum and gas, Metal mining and Nonmetal mining are merged into the larger sector of Mining; (2) All the manufacturing sectors (those belonging to Light and Heavy industry category introduced in Section S3) are merged into Manufacturing; (3) The Electricity \& hot water production and supply and Gas \& water production and supply sectors are merged into Power sector. To match the data between rural and urban investment, we assume the rural investment of these larger categories to the corresponding industry sectors according to the structure of urban investment. In this way, we get the rural and urban investment data for the 26 sectors. 
Table S1. Percentage of rural investment in the sum of rural and urban investment for each province and sector.

\begin{tabular}{|c|c|c|c|c|c|c|c|c|c|c|c|c|}
\hline & Agriculture & Mining & Manufacturing & Power & Construction & $\begin{array}{c}\text { Transport and } \\
\text { storage }\end{array}$ & $\begin{array}{c}\text { Wholesale and } \\
\text { retailing }\end{array}$ & $\begin{array}{l}\text { Hotel and } \\
\text { restaurant }\end{array}$ & $\begin{array}{c}\text { Leasing and } \\
\text { commercial } \\
\text { services }\end{array}$ & $\begin{array}{l}\text { Scientific } \\
\text { research }\end{array}$ & $\begin{array}{c}\text { Other } \\
\text { services }\end{array}$ & Total \\
\hline Beijing & $93.1 \%$ & $8.2 \%$ & $19.8 \%$ & $8.7 \%$ & $21.2 \%$ & $7.3 \%$ & $36.0 \%$ & $40.6 \%$ & $19.5 \%$ & $7.6 \%$ & $7.5 \%$ & $9.5 \%$ \\
\hline Tianjin & $47.9 \%$ & $0.1 \%$ & $9.6 \%$ & $2.0 \%$ & $17.8 \%$ & $3.2 \%$ & $6.4 \%$ & $4.8 \%$ & $7.4 \%$ & $0.0 \%$ & $3.3 \%$ & $6.1 \%$ \\
\hline Hebei & $48.8 \%$ & $19.9 \%$ & $16.4 \%$ & $5.2 \%$ & $13.8 \%$ & $8.8 \%$ & $12.9 \%$ & $6.2 \%$ & $3.7 \%$ & $3.8 \%$ & $12.9 \%$ & $15.0 \%$ \\
\hline Shanxi & $40.6 \%$ & $4.6 \%$ & $4.8 \%$ & $1.5 \%$ & $3.7 \%$ & $4.2 \%$ & $8.4 \%$ & $5.8 \%$ & $0.1 \%$ & $11.2 \%$ & $13.1 \%$ & $8.8 \%$ \\
\hline Inner Mongolia & $31.7 \%$ & $0.7 \%$ & $0.1 \%$ & $0.2 \%$ & $4.3 \%$ & $0.8 \%$ & $0.8 \%$ & $6.8 \%$ & $0.0 \%$ & $3.5 \%$ & $2.1 \%$ & $1.7 \%$ \\
\hline Liaoning & $46.4 \%$ & $11.5 \%$ & $5.1 \%$ & $4.5 \%$ & $12.4 \%$ & $3.7 \%$ & $2.6 \%$ & $4.7 \%$ & $1.6 \%$ & $0.4 \%$ & $4.0 \%$ & $5.7 \%$ \\
\hline Jilin & $45.1 \%$ & $12.0 \%$ & $3.7 \%$ & $7.2 \%$ & $7.3 \%$ & $8.1 \%$ & $2.5 \%$ & $1.4 \%$ & $0.0 \%$ & $2.1 \%$ & $5.5 \%$ & $6.5 \%$ \\
\hline Heilongjiang & $50.5 \%$ & $0.4 \%$ & $1.2 \%$ & $0.4 \%$ & $5.3 \%$ & $5.1 \%$ & $0.9 \%$ & $1.5 \%$ & $0.3 \%$ & $0.1 \%$ & $6.7 \%$ & $7.2 \%$ \\
\hline Shanghai & $68.1 \%$ & $0.5 \%$ & $27.1 \%$ & $1.0 \%$ & $14.1 \%$ & $1.6 \%$ & $61.5 \%$ & $25.5 \%$ & $13.2 \%$ & $22.9 \%$ & $2.6 \%$ & $8.9 \%$ \\
\hline Jiangsu & $74.8 \%$ & $25.4 \%$ & $35.0 \%$ & $19.5 \%$ & $28.6 \%$ & $13.9 \%$ & $24.6 \%$ & $20.1 \%$ & $14.7 \%$ & $13.9 \%$ & $11.3 \%$ & $24.8 \%$ \\
\hline Zhejiang & $76.1 \%$ & $93.0 \%$ & $56.4 \%$ & $15.8 \%$ & $39.4 \%$ & $12.9 \%$ & $25.9 \%$ & $25.2 \%$ & $14.6 \%$ & $17.6 \%$ & $15.9 \%$ & $31.3 \%$ \\
\hline Anhui & $56.8 \%$ & $11.5 \%$ & $8.2 \%$ & $7.2 \%$ & $16.2 \%$ & $12.8 \%$ & $8.8 \%$ & $5.8 \%$ & $7.3 \%$ & $4.4 \%$ & $11.6 \%$ & $11.2 \%$ \\
\hline Fujian & $59.0 \%$ & $43.0 \%$ & $11.2 \%$ & $4.0 \%$ & $25.7 \%$ & $5.6 \%$ & $8.3 \%$ & $6.1 \%$ & $2.7 \%$ & $6.1 \%$ & $11.8 \%$ & $11.4 \%$ \\
\hline Jiangxi & $52.6 \%$ & $24.0 \%$ & $3.5 \%$ & $6.3 \%$ & $24.2 \%$ & $13.2 \%$ & $5.9 \%$ & $5.0 \%$ & $6.9 \%$ & $0.8 \%$ & $16.1 \%$ & $10.1 \%$ \\
\hline Shandong & $66.0 \%$ & $21.6 \%$ & $19.7 \%$ & $14.6 \%$ & $25.5 \%$ & $17.6 \%$ & $16.3 \%$ & $12.5 \%$ & $9.3 \%$ & $16.9 \%$ & $15.5 \%$ & $19.0 \%$ \\
\hline Henan & $58.1 \%$ & $9.1 \%$ & $8.1 \%$ & $6.3 \%$ & $18.9 \%$ & $16.6 \%$ & $17.1 \%$ & $8.8 \%$ & $8.4 \%$ & $20.5 \%$ & $27.3 \%$ & $17.5 \%$ \\
\hline Hubei & $42.8 \%$ & $20.2 \%$ & $4.3 \%$ & $2.7 \%$ & $22.7 \%$ & $6.4 \%$ & $4.0 \%$ & $5.0 \%$ & $1.6 \%$ & $4.2 \%$ & $10.2 \%$ & $8.5 \%$ \\
\hline Hunan & $40.0 \%$ & $19.3 \%$ & $6.7 \%$ & $10.5 \%$ & $15.2 \%$ & $6.8 \%$ & $6.6 \%$ & $9.6 \%$ & $2.7 \%$ & $13.5 \%$ & $12.1 \%$ & $10.8 \%$ \\
\hline Guangdong & $71.6 \%$ & $35.1 \%$ & $40.1 \%$ & $15.6 \%$ & $58.2 \%$ & $9.8 \%$ & $36.8 \%$ & $28.5 \%$ & $19.4 \%$ & $16.8 \%$ & $11.5 \%$ & $20.8 \%$ \\
\hline Guangxi & $39.1 \%$ & $14.6 \%$ & $4.5 \%$ & $5.7 \%$ & $13.9 \%$ & $10.2 \%$ & $2.7 \%$ & $3.0 \%$ & $2.5 \%$ & $5.3 \%$ & $11.8 \%$ & $9.9 \%$ \\
\hline Hainan & $58.3 \%$ & $0.0 \%$ & $0.7 \%$ & $4.1 \%$ & $1.3 \%$ & $1.2 \%$ & $7.1 \%$ & $0.9 \%$ & $0.1 \%$ & $19.7 \%$ & $4.3 \%$ & $4.6 \%$ \\
\hline Chongqing & $37.2 \%$ & $18.8 \%$ & $4.6 \%$ & $6.5 \%$ & $20.7 \%$ & $5.5 \%$ & $3.1 \%$ & $6.1 \%$ & $2.3 \%$ & $3.7 \%$ & $7.8 \%$ & $8.4 \%$ \\
\hline Sichuan & $55.1 \%$ & $40.7 \%$ & $9.5 \%$ & $9.1 \%$ & $71.4 \%$ & $13.4 \%$ & $16.0 \%$ & $13.0 \%$ & $6.8 \%$ & $13.6 \%$ & $24.0 \%$ & $19.3 \%$ \\
\hline
\end{tabular}


Table $\mathbf{S} 1$ continued.

\begin{tabular}{|c|c|c|c|c|c|c|c|c|c|c|c|c|}
\hline Agriculture & Mining & Manufacturing & Power & Construction & $\begin{array}{c}\text { Transport } \\
\text { and } \\
\text { storage }\end{array}$ & $\begin{array}{c}\text { Wholesale } \\
\text { and } \\
\text { retailing }\end{array}$ & $\begin{array}{l}\text { Hotel and } \\
\text { restaurant }\end{array}$ & $\begin{array}{c}\text { Leasing } \\
\text { and } \\
\text { commercial } \\
\text { services }\end{array}$ & $\begin{array}{c}\text { Scientific } \\
\text { research }\end{array}$ & $\begin{array}{c}\text { Other } \\
\text { services }\end{array}$ & Total & Agriculture \\
\hline Guizhou & $68.4 \%$ & $49.4 \%$ & $4.3 \%$ & $3.2 \%$ & $24.1 \%$ & $5.8 \%$ & $8.6 \%$ & $3.8 \%$ & $3.5 \%$ & $4.3 \%$ & $13.7 \%$ & $15.5 \%$ \\
\hline Yunnan & $47.2 \%$ & $9.9 \%$ & $2.9 \%$ & $1.2 \%$ & $45.0 \%$ & $4.7 \%$ & $3.2 \%$ & $16.0 \%$ & $8.3 \%$ & $7.9 \%$ & $10.4 \%$ & $8.8 \%$ \\
\hline Shaanxi & $26.7 \%$ & $1.3 \%$ & $1.2 \%$ & $1.2 \%$ & $6.0 \%$ & $6.6 \%$ & $5.0 \%$ & $8.2 \%$ & $0.9 \%$ & $0.4 \%$ & $7.8 \%$ & $5.7 \%$ \\
\hline Gansu & $40.9 \%$ & $3.8 \%$ & $4.6 \%$ & $3.9 \%$ & $13.0 \%$ & $7.2 \%$ & $10.2 \%$ & $10.6 \%$ & $2.8 \%$ & $7.5 \%$ & $16.2 \%$ & $11.5 \%$ \\
\hline Qinghai & $64.0 \%$ & $11.7 \%$ & $6.0 \%$ & $2.7 \%$ & $28.1 \%$ & $14.8 \%$ & $6.2 \%$ & $12.2 \%$ & $2.4 \%$ & $25.3 \%$ & $18.8 \%$ & $15.8 \%$ \\
\hline Ningxia & $56.2 \%$ & $3.1 \%$ & $4.3 \%$ & $3.1 \%$ & $38.6 \%$ & $31.8 \%$ & $7.9 \%$ & $6.0 \%$ & $33.3 \%$ & $33.4 \%$ & $10.2 \%$ & $10.4 \%$ \\
\hline Xinjiang & $54.9 \%$ & $2.3 \%$ & $5.9 \%$ & $4.4 \%$ & $29.9 \%$ & $10.9 \%$ & $7.3 \%$ & $4.5 \%$ & $12.8 \%$ & $7.4 \%$ & $10.8 \%$ & $10.6 \%$ \\
\hline China & $51.0 \%$ & $12.3 \%$ & $15.5 \%$ & $6.7 \%$ & $20.7 \%$ & $8.7 \%$ & $12.9 \%$ & $11.4 \%$ & $7.7 \%$ & $8.8 \%$ & $11.9 \%$ & $13.8 \%$ \\
\hline
\end{tabular}


S6. Per-capita direct emissions of $\mathrm{NO}_{\mathrm{x}}, \mathrm{SO}_{2}$ and primary $\mathrm{PM}_{2.5}$ for rural and urban households

The emission inventory collects data for the household direct emissions of $\mathrm{NO}_{\mathrm{x}}$, $\mathrm{SO}_{2}$ and primary $\mathrm{PM}_{2.5}$, so the calculation process does not involve MRIO model. Rural and urban populations of each province are obtained from China Statistical Yearbook. ${ }^{16}$ Results for $\mathrm{NO}_{\mathrm{x}}, \mathrm{SO}_{2}$ and primary $\mathrm{PM}_{2.5}$ are shown in Figures $\mathrm{S} 5$, S6 and $\mathrm{S} 7$, respectively.

Rural residents have higher direct emission level of $\mathrm{NO}_{\mathrm{x}}(0.8 \mathrm{~kg} /$ person, accounting for $26.4 \%$ of the total consumption-driven emission) than their urban counterparts $(0.4 \mathrm{~kg} /$ person, accounting for $5.6 \%$ of the total consumption-driven emission), as is shown in Figure S5. Inner Mongolia stands out as an exception, with rather high urban direct $\mathrm{NO}_{\mathrm{x}}$ emission of $2.24 \mathrm{~kg} / \mathrm{person}$, which is slightly higher than its rural level at $2.20 \mathrm{~kg} /$ person. Nationally, the rural emission is mainly driven by heating (41.5\%) and cooking \& hot water (46.2\%) demands, while the urban emission is mainly from heating (38.1\%) and household transport (54.7\%) activities, since urban residents have more car possession and higher travel demand. For climate reasons, there are no space heating emissions in some southern provinces, such as Guangdong, Guangxi, Hainan and Yunnan. 
(a) Rural

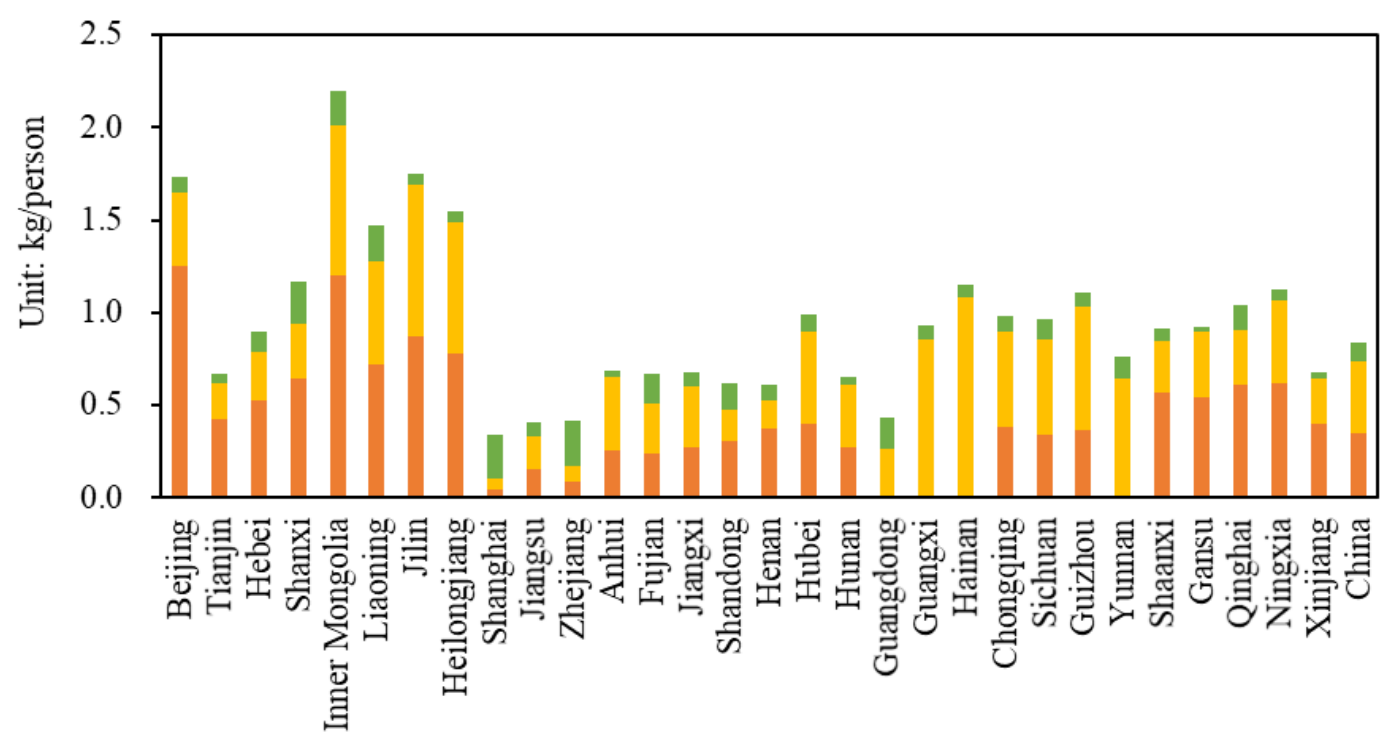

(b) Urban

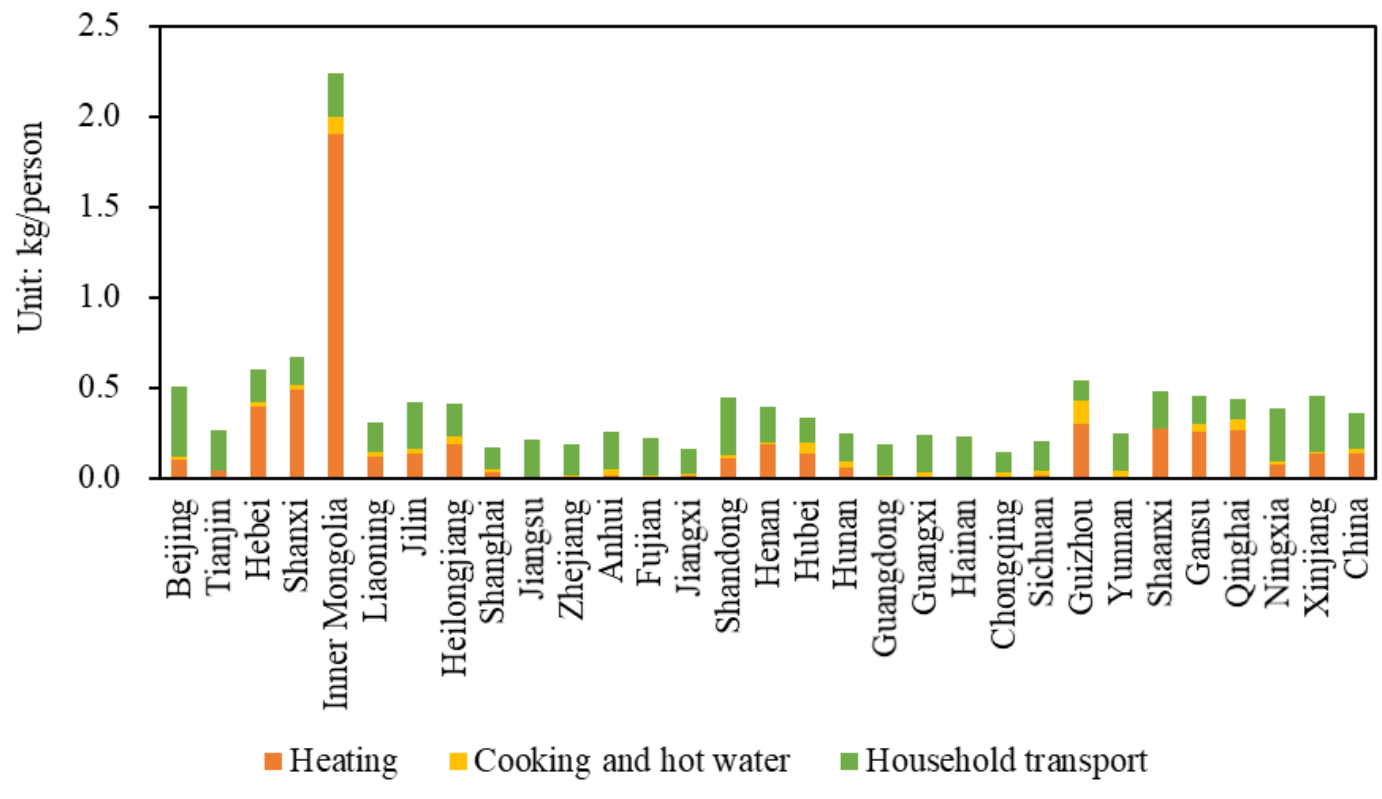

Figure S5. The per-capita direct emissions of $\mathrm{NO}_{\mathrm{x}}$ resulted from rural (a) and urban (b) household energy use in 2012. 
(a) Rural

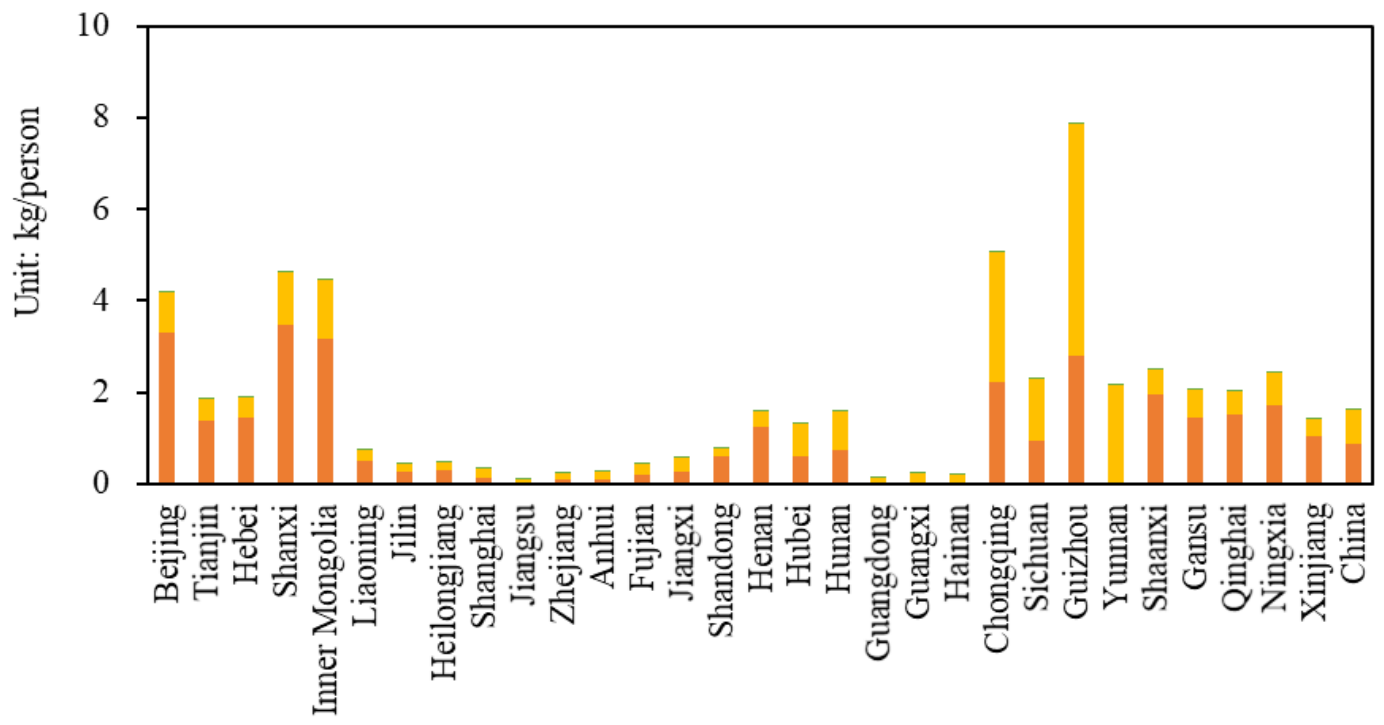

(b) Urban

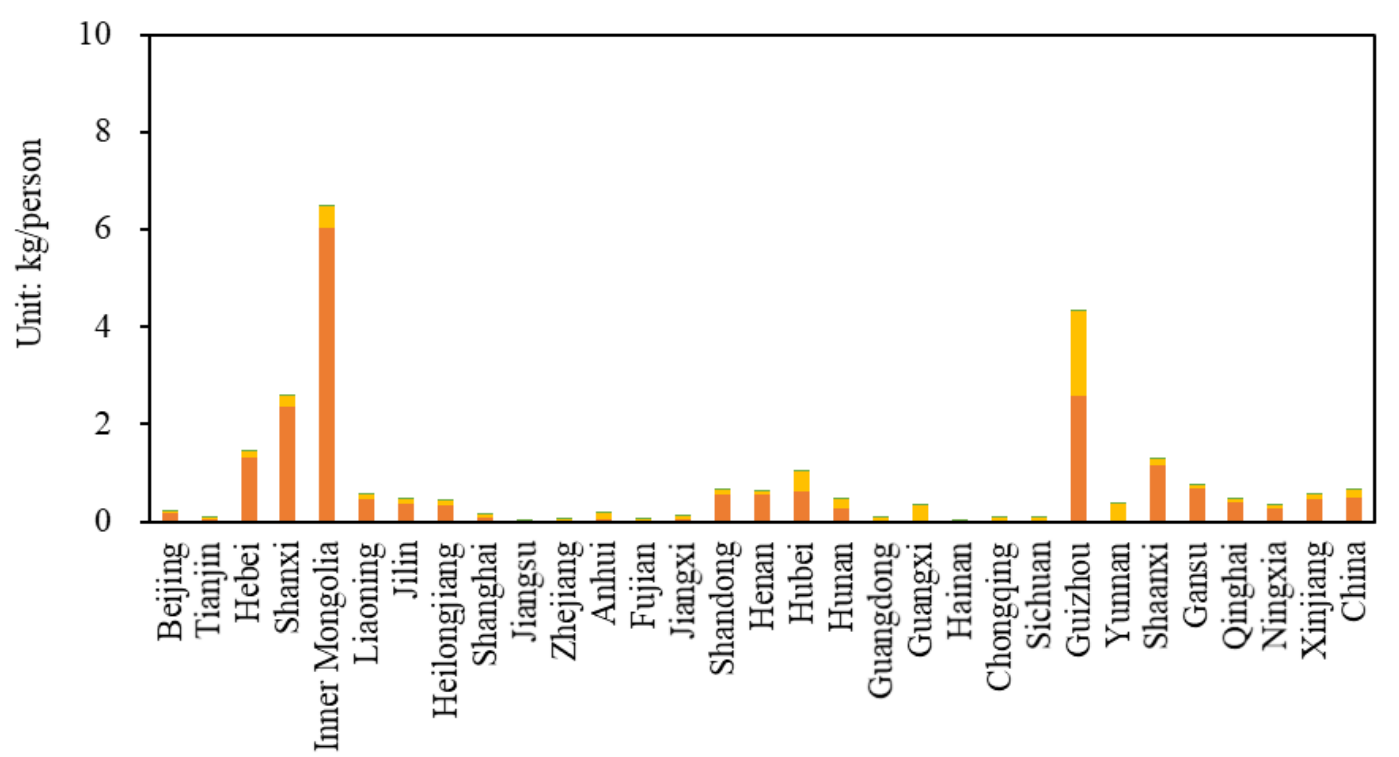

Heating $\quad$ Cooking and hot water $\quad$ Household transport

Figure S6. The per-capita direct emissions of $\mathrm{SO}_{2}$ resulted from rural (a) and urban (b) household energy use in 2012.

Similar to $\mathrm{NO}_{\mathrm{x}}$, the rural $\mathrm{SO}_{2}$ direct emission (1.6 kg/person, accounting for $43.1 \%$ of the total consumption-driven emission) is also higher than the urban one $(0.7$ $\mathrm{kg} /$ person, accounting for $10.8 \%$ of the total consumption-driven emission). Due to consumption of high-sulfur coal ${ }^{17,18}$, the southwestern region witnesses high $\mathrm{SO}_{2}$ 
emissions, and Guizhou province holds the highest rural $\mathrm{SO}_{2}$ emission level of 7.9 $\mathrm{kg} /$ person. For Inner Mongolia, the urban direct emission (6.5 $\mathrm{kg} \mathrm{SO}_{2} /$ person) is still higher than the rural one (4.5 $\mathrm{kg} \mathrm{SO}_{2} /$ person). On a national average, the rural direct emission of $\mathrm{SO}_{2}$ is mainly from heating (53.6\%) and cooking \& hot water (46.0\%). Due to warmer climate in southern China, people in southern provinces such as Chongqing, Sichuan, Guizhou and Yunnan have less heating demand, and thus cooking \& hot water emission holds a larger proportion than heating emission in the rural areas. The urban direct emission is mainly from heating (76.0\%) and cooking plays a much less role (22.0\%), as urban residents mainly use electricity or natural gas to cook.

The direct emission of primary $\mathrm{PM}_{2.5}$ shows the largest rural-urban gap, with the national average direct emission level of $3.8 \mathrm{~kg} /$ person (accounting for $81.2 \%$ of the rural total consumption-driven emission) in rural areas, compared to $0.2 \mathrm{~kg} / \mathrm{person}$ (accounting for $10.6 \%$ of the urban total consumption-driven emission) in urban areas. The rural emission is mainly from heating (44.7\%) and cooking \& hot water (54.9\%), while the urban emission is mainly from heating $(67.5 \%)$ on national average, and cooking \& hot water only accounts for $22.4 \%$. The intense use of solid fuels (fossil fuels and biomass) and relatively low burning efficiency ${ }^{19}$ in rural areas is the main reason for the high rural emission. 
(a) Rural

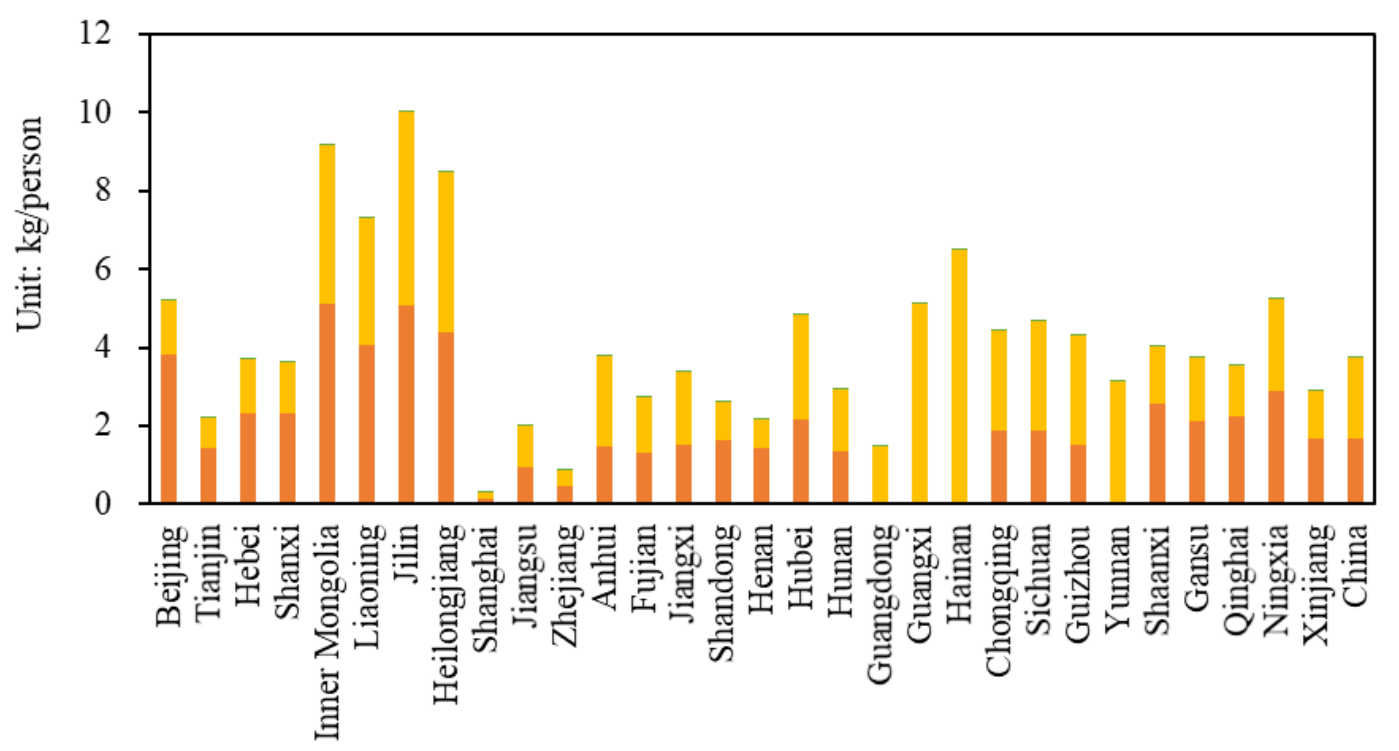

(b) Urban

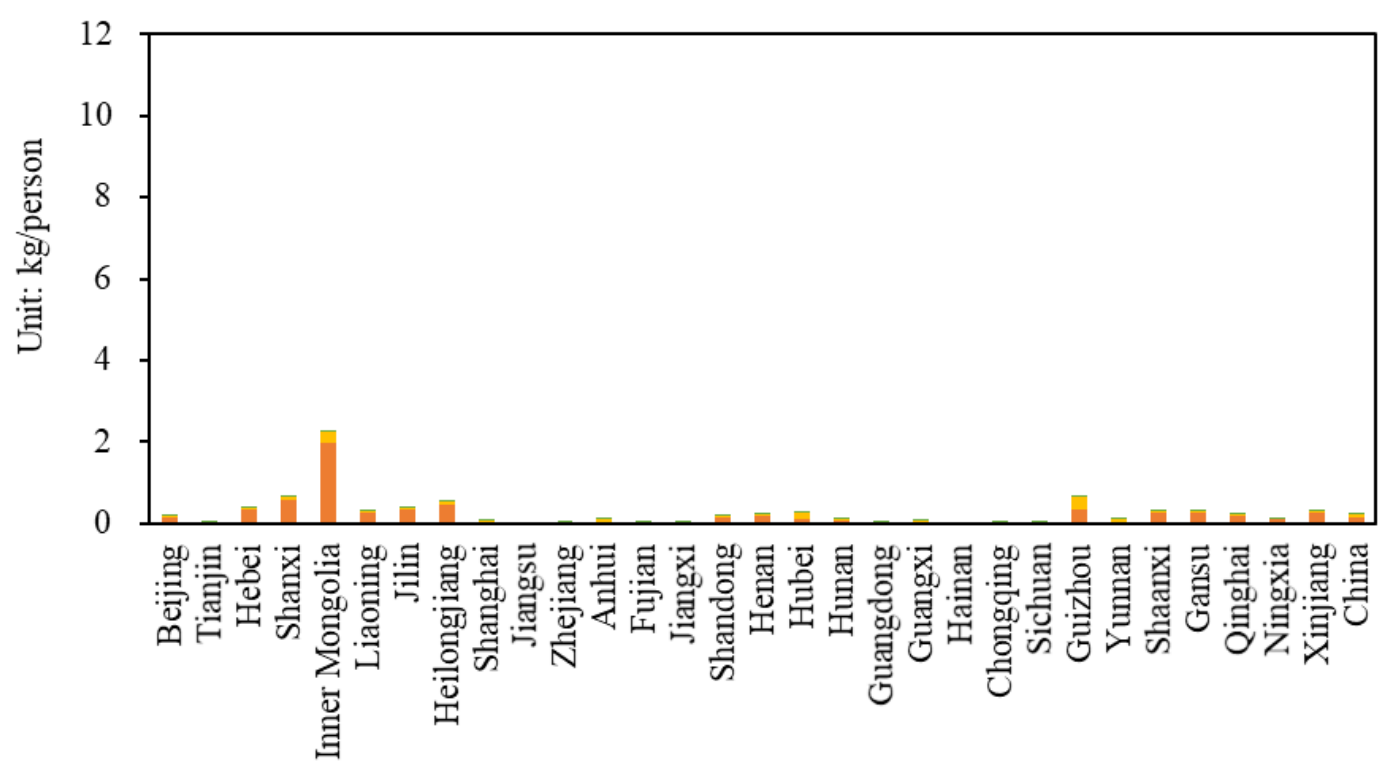

Heating $\square$ Cooking and hot water $\square$ Household transport

Figure S7. The per-capita direct emissions of primary $\mathrm{PM}_{2.5}$ resulted from rural (a) and urban (b) household energy use in 2012. 


\section{S7. Per-capita indirect $\mathrm{NO}_{\mathrm{x}}, \mathrm{SO}_{2}$ and primary $\mathrm{PM}_{2.5}$ emissions driven by consumption for rural and urban households}

The indirect emission driven by consumption refers to the emission embodied in household product and service consumption. It includes air pollutants emitted during the product production and supply procedure to satisfy the final demands. The emission inventory and environmentally-extended MRIO model are used for calculation. Figures S8, S9 and S10 show the per-capita indirect emissions of $\mathrm{NO}_{\mathrm{x}}, \mathrm{SO}_{2}$ and primary $\mathrm{PM}_{2.5}$ driven by consumption for rural and urban households. As for sectoral structure, we allocate the consumption-driven emissions to the 'producers', and the emission from each sector refers to the actual pollutants emitted from them to satisfy the final demand (see Section S4).

Generally, the urban households have higher indirect emission level than their rural counterparts. The national average per-capita indirect $\mathrm{NO}_{\mathrm{x}}$ emission driven by consumption is $2.3 \mathrm{~kg} /$ person for rural residents, with $36.4 \%$ from utility industry, $21.6 \%$ from service sector, $20.6 \%$ from heavy industry and $19.6 \%$ from agriculture. The indirect $\mathrm{NO}_{\mathrm{x}}$ emission for urban residents is $6.0 \mathrm{~kg} /$ person on average, with $40.4 \%$ from utility industry, $23.7 \%$ from service sector, followed by heavy industry accounting for $17.2 \%$ and agriculture accounting for $17.0 \%$. 
(a) Rural

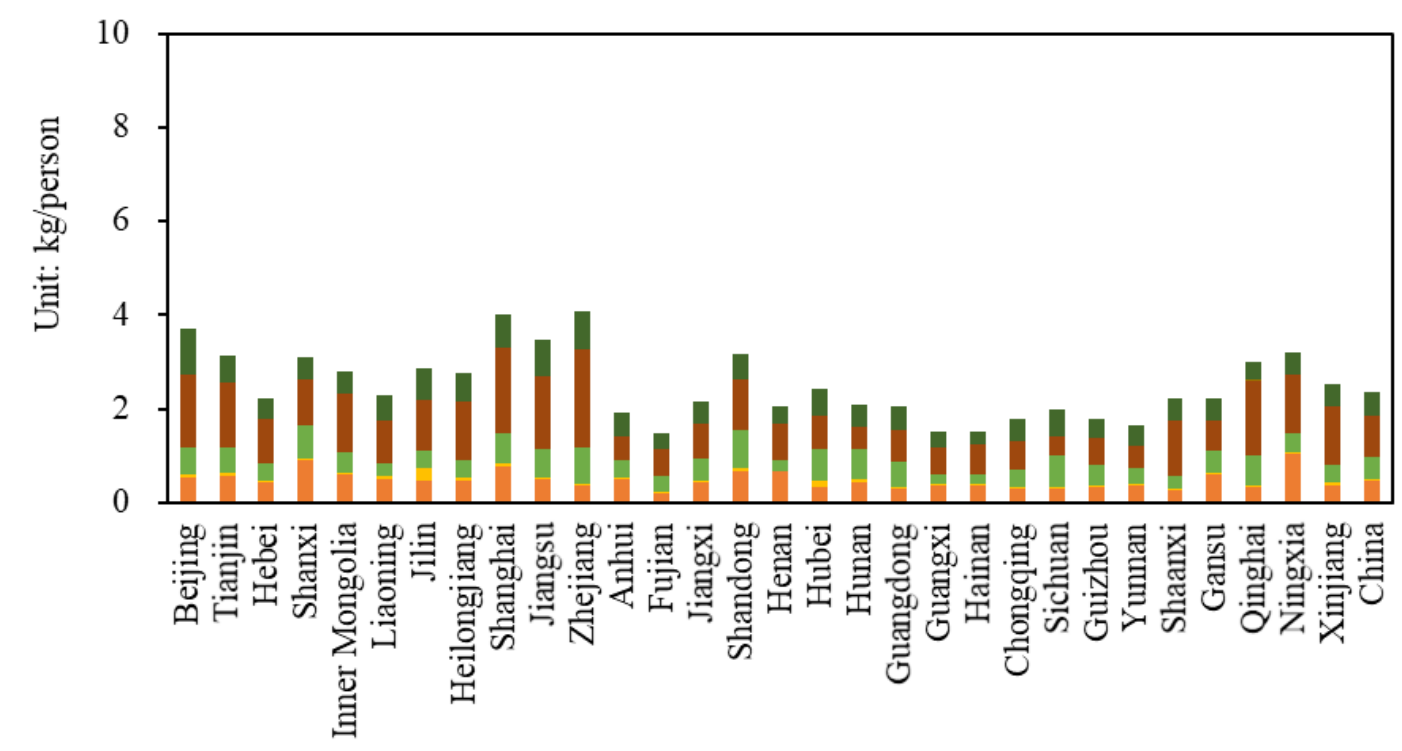

(b) Urban

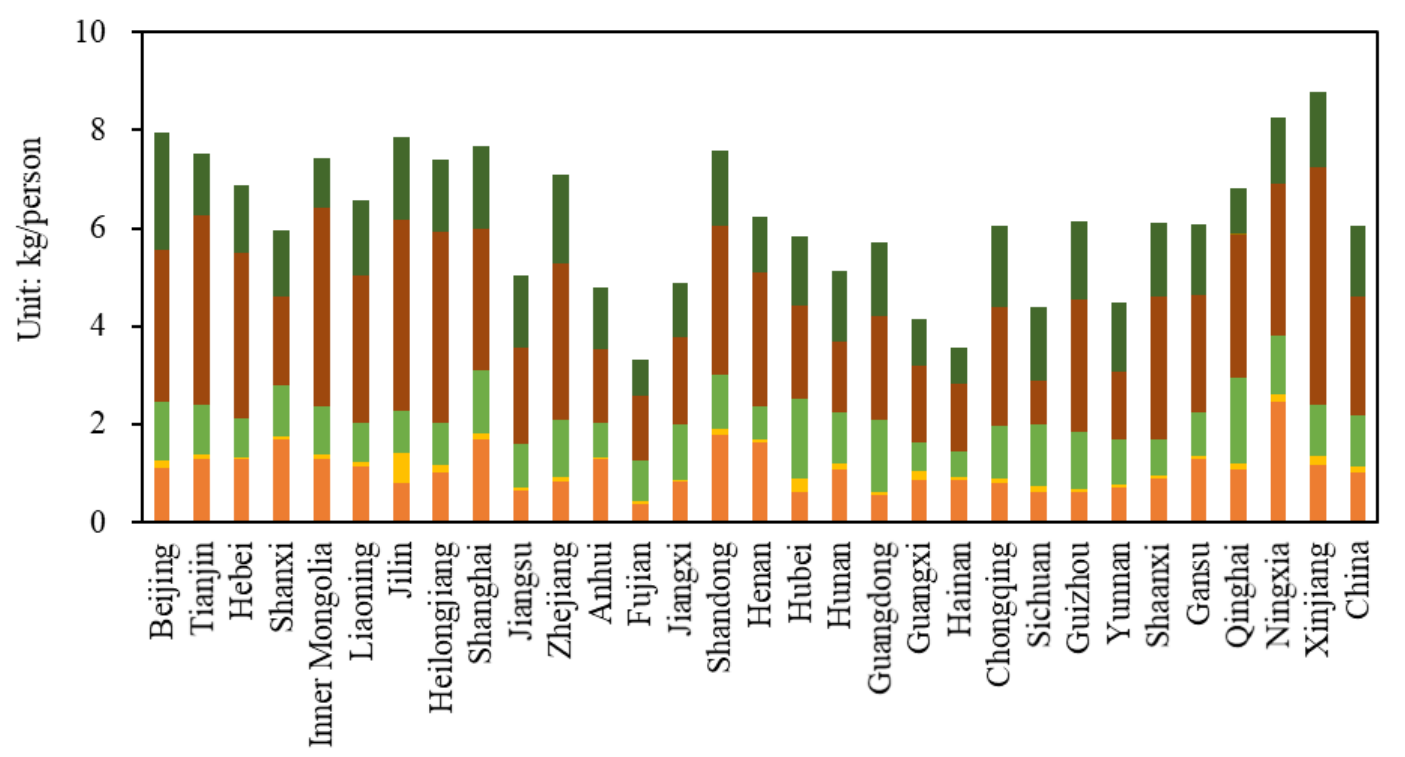

$\square$ Agriculture $\square$ Light industry $\square$ Heavy industry $\square$ Utility industry $\square$ Construction $\square$ Service

Figure S8. The per-capita indirect emissions of $\mathrm{NO}_{\mathrm{x}}$ embodied in rural (a) and urban (b) household consumption in 2012.

The national average rural per-capita $\mathrm{SO}_{2}$ emission embodied in consumption is $2.1 \mathrm{~kg} /$ person, with $42.3 \%$ from non-electricity heavy industry and $37.2 \%$ from utility industry. For urban households, the $\mathrm{SO}_{2}$ emission level is $5.4 \mathrm{~kg} /$ person, and emissions 
from non-electricity heavy industry and utility industry account for $40.1 \%$ and $39.5 \%$ of the total. Compared to $\mathrm{NO}_{\mathrm{x}}$, the emission sources of $\mathrm{SO}_{2}$ are more concentrated, which is mainly associated with heavy industry and utility industry.

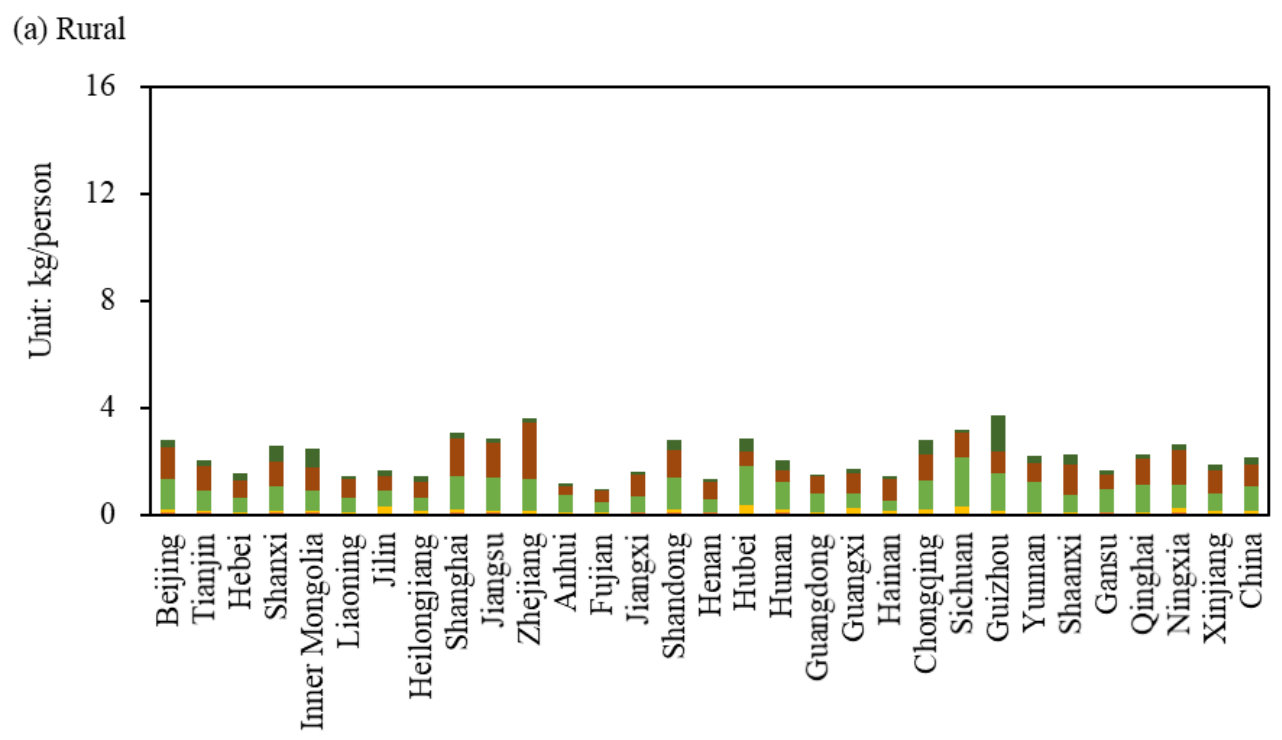

(b) Urban

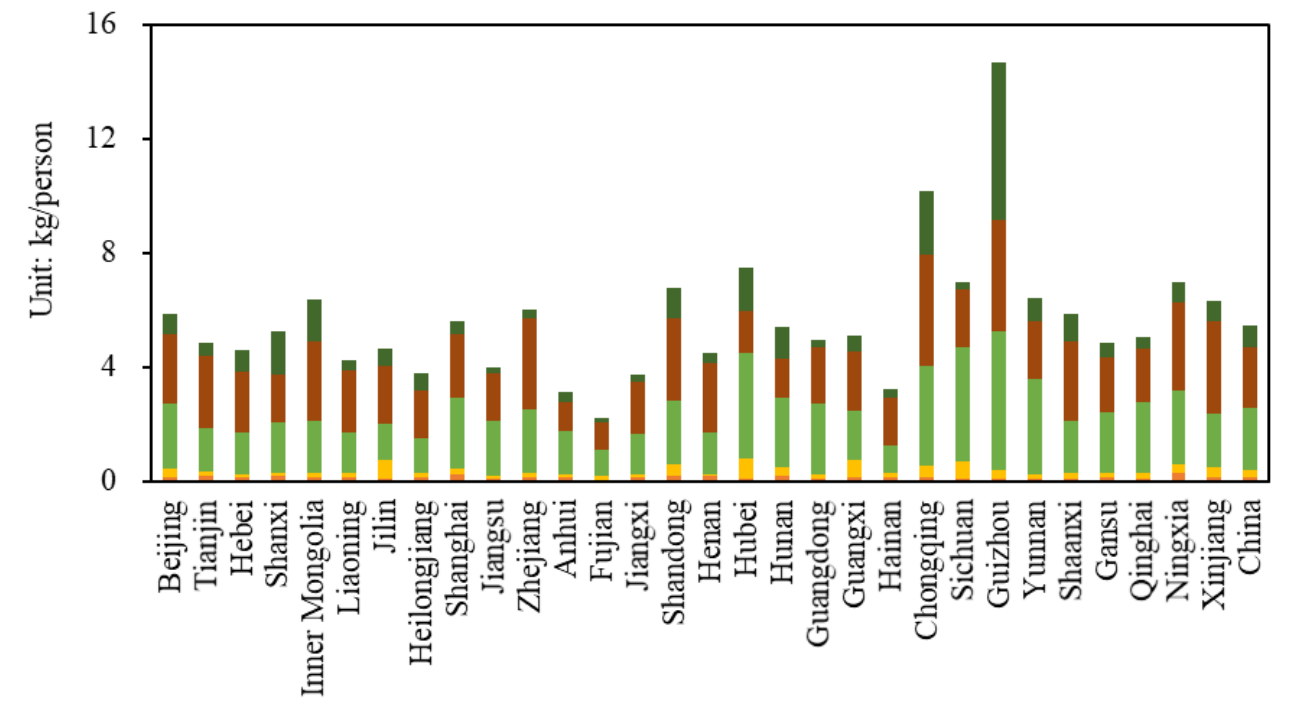

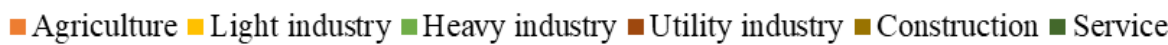

Figure S9. The per-capita indirect emissions of $\mathrm{SO}_{2}$ embodied in rural (a) and urban (b) household consumption in 2012. 
(a) Rural

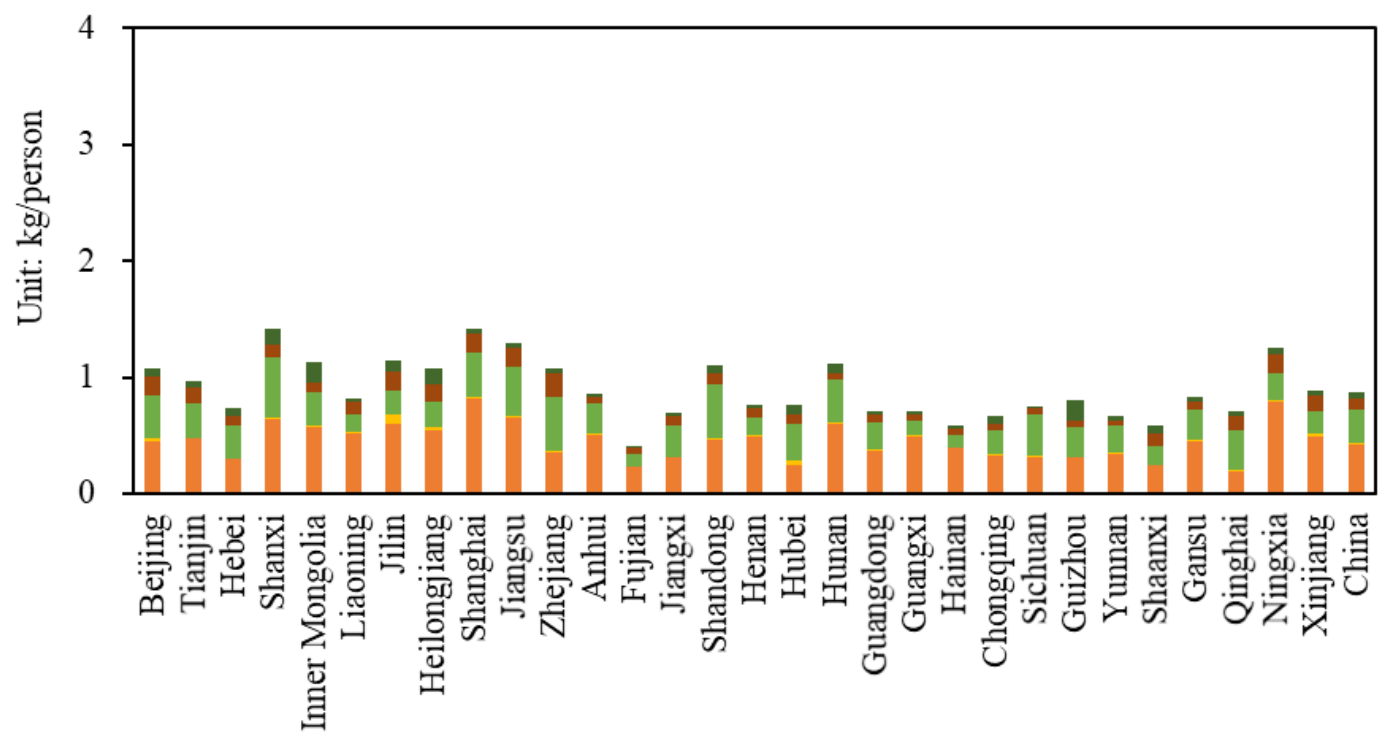

(b) Urban

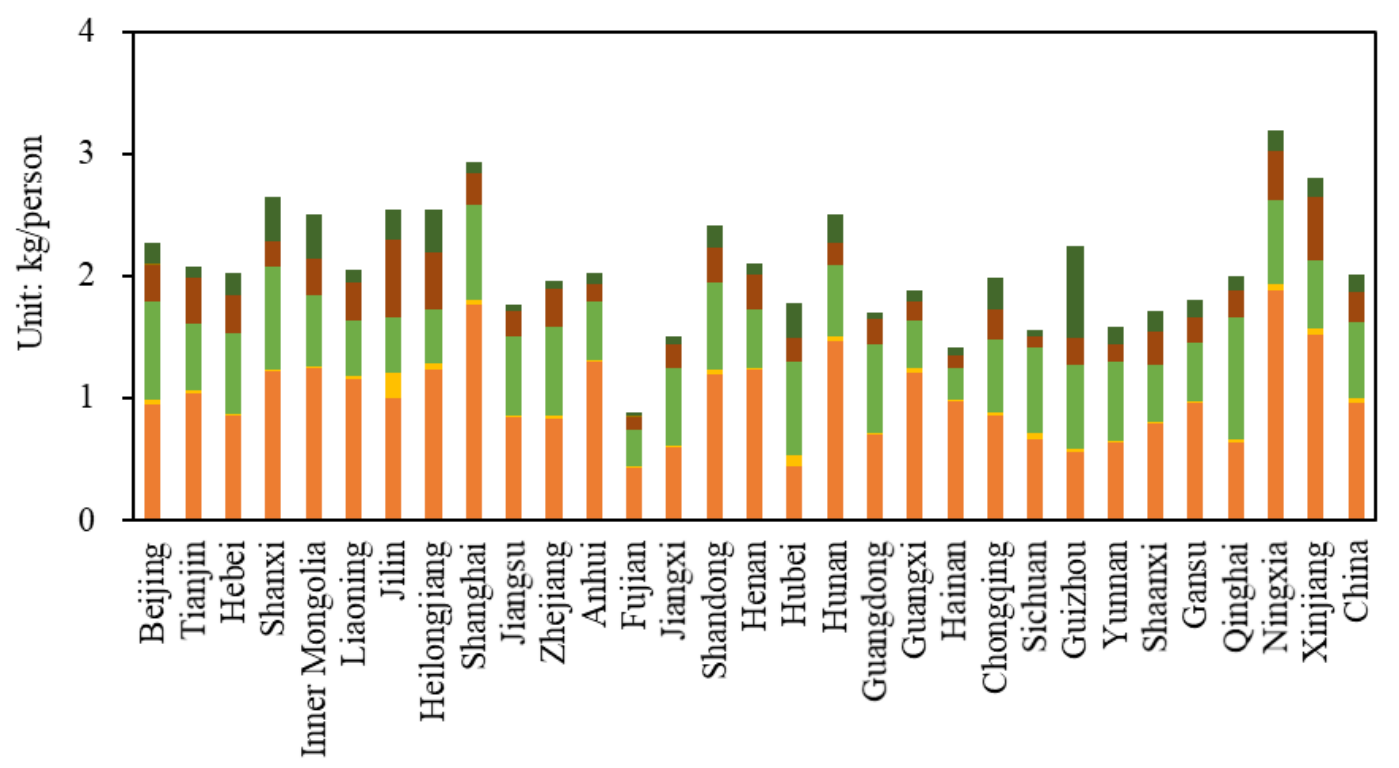

agriculture $\square$ Light industry $\square$ Heavy industry $\square$ Utility industry $\square$ Construction $\square$ Service

Figure S10. The per-capita indirect emissions of primary $\mathrm{PM}_{2.5}$ embodied in rural (a) and urban (b) household consumption in 2012.

The rural indirect primary $\mathrm{PM}_{2.5}$ emission driven by consumption is $0.9 \mathrm{~kg} / \mathrm{person}$ on national average, and its major sources are agriculture, which accounts for $49.3 \%$, 
and heavy industry, $32.6 \%$. The urban emission level is $2.0 \mathrm{~kg} / \mathrm{person}$, with $48.0 \%$ from agriculture and $30.6 \%$ from heavy industry. Different from $\mathrm{NO}_{\mathrm{x}}$ and $\mathrm{SO}_{2}$, utility industry is not the main source of primary $\mathrm{PM}_{2.5}$, because the emissions of primary $\mathrm{PM}_{2.5}$ from electricity generation have been well controlled ${ }^{20,21}$. Instead, agriculture contributes more to the emission of primary $\mathrm{PM}_{2.5}$.

\section{S8. Per-capita indirect $\mathrm{NO}_{\mathrm{x}}, \mathrm{SO}_{2}$ and primary $\mathrm{PM}_{2.5}$ emissions driven by investment for rural and urban residents}

Indirect emission driven by investment refers to the emission embodied in percapita investment, which is the pollutants emitted during the production and supply procedure of materials needed by the investment process. In the calculation process, the emission inventory and environmentally-extended MRIO model are used. Figures S11, $\mathrm{S} 12$ and $\mathrm{S} 13$ show the per-capita indirect emissions of $\mathrm{NO}_{\mathrm{x}}, \mathrm{SO}_{2}$ and primary $\mathrm{PM}_{2.5}$ driven by investment for rural and urban residents. In terms of sectoral structure, we allocate the investment-driven emissions to the 'producers', and the emission from each sector refers to the actual pollutants emitted from them to satisfy the final demand (see Section S4).

On national level, the urban emission level embodied in investment is higher than the rural level. For $\mathrm{NO}_{\mathrm{x}}$, the urban emission embodied in investment is $15.0 \mathrm{~kg} /$ person, with $44.5 \%$ from heavy industry and $32.9 \%$ from utility industry. The rural emission is only $4.4 \mathrm{~kg} /$ person, with $50.1 \%$ from heavy industry and $28.7 \%$ from utility industry. While for some developed coastal provinces such as Zhejiang and Guangdong 
provinces, and the highly developed municipalities of Beijing and Shanghai, the rural emission level is higher than the urban one. Take Beijing as an example: the urban $\mathrm{NO}_{\mathrm{x}}$ emission driven by investment is $10.5 \mathrm{~kg} /$ person, while the rural emission is 15.7 $\mathrm{kg} /$ person, which is $48.9 \%$ higher than the urban counterpart.
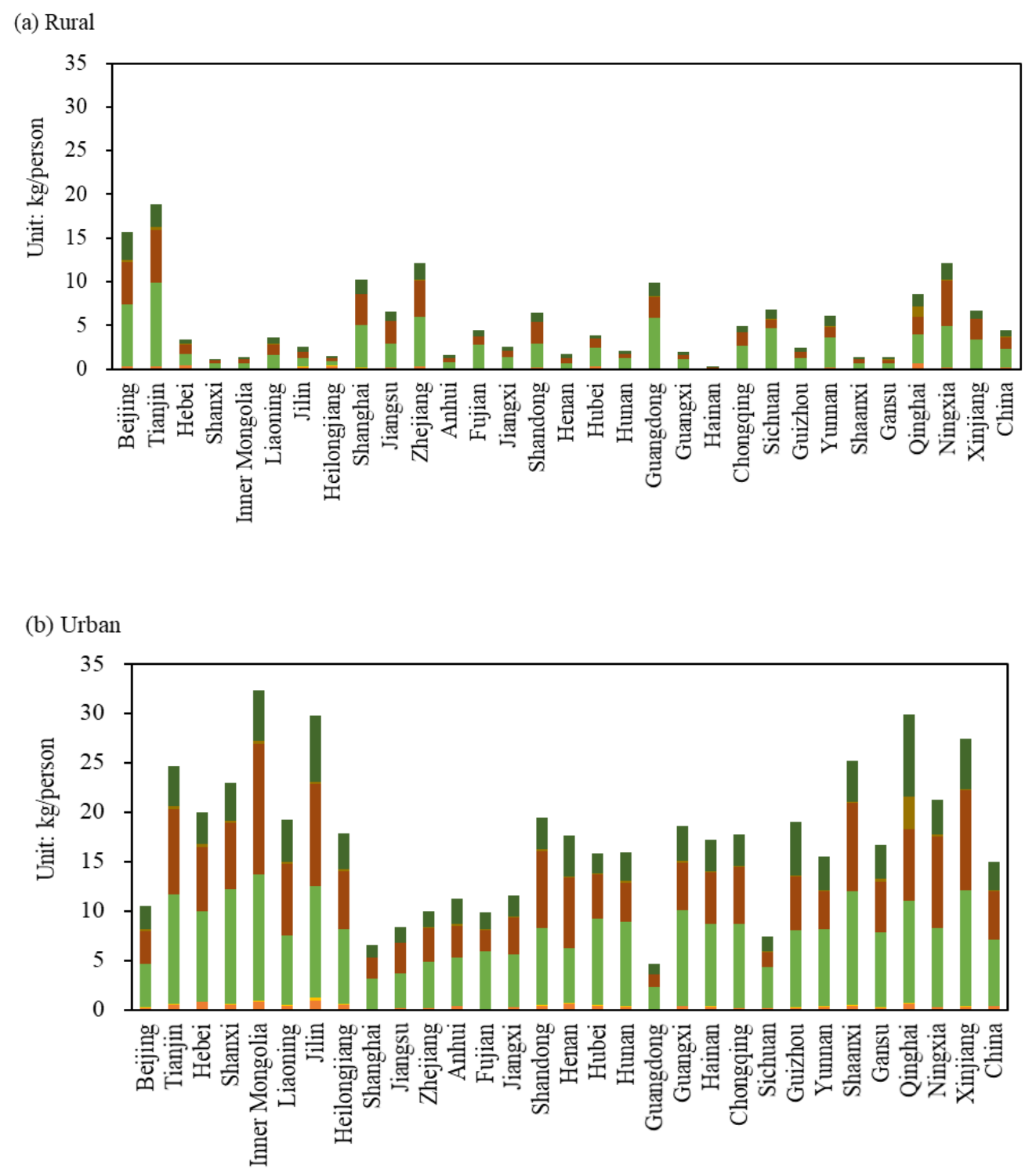

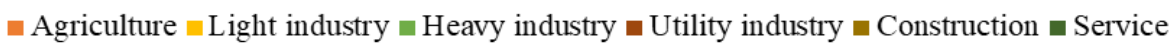

Figure S11. The per-capita indirect emissions of $\mathrm{NO}_{\mathrm{x}}$ embodied in rural (a) and urban (b) investment in 2012 . 
The urban $\mathrm{SO}_{2}$ emission is $15.6 \mathrm{~kg} /$ person, and the heavy and utility industries are still the main sources which contribute $63.4 \%$ and $28.4 \%$ respectively. For rural population, the emission is $4.6 \mathrm{~kg} /$ person, with $66.7 \%$ from heavy industry and $27.4 \%$ from utility industry. Similarly, in Beijing, Shanghai, Zhejiang and Guangdong, the rural emission level is higher than the urban one.

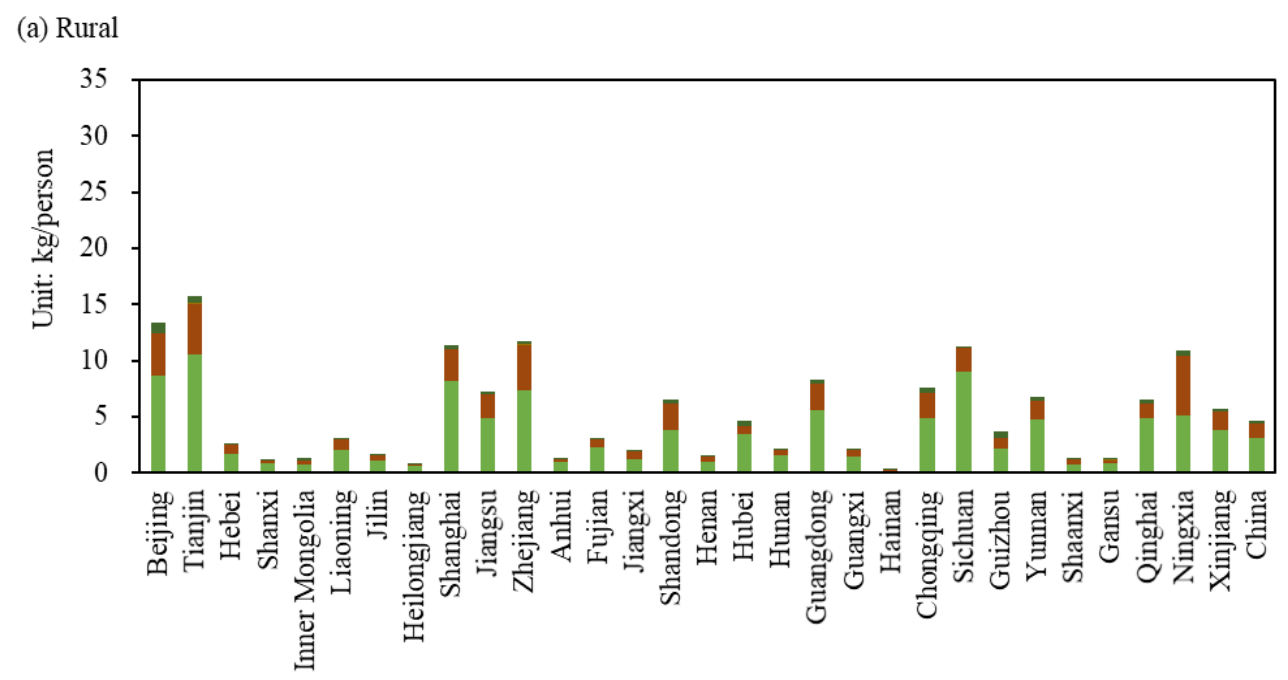

(b) Urban

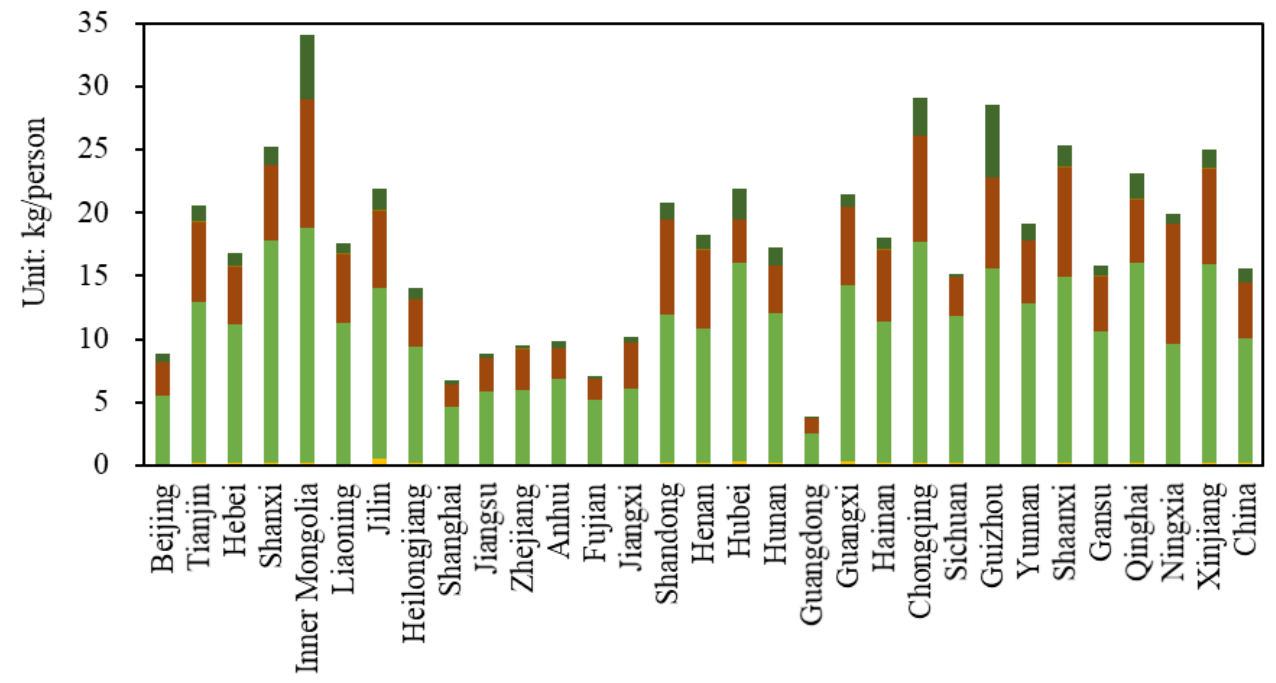

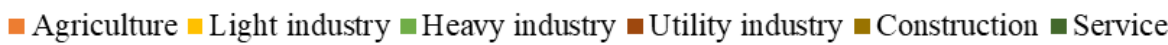

Figure S12. The per-capita indirect emissions of $\mathrm{SO}_{2}$ embodied in rural (a) and urban (b) investment in 2012. 
For primary $\mathrm{PM}_{2.5}$, the urban emission level is $5.4 \mathrm{~kg} / \mathrm{person}$, compared to the rural level of $1.6 \mathrm{~kg} /$ person. Different from the other two kinds of air pollutants, emission of primary $\mathrm{PM}_{2.5}$ embodied in investment is almost all from heavy industry, which contributes $79.6 \%$ to urban emission and $80.3 \%$ to rural.

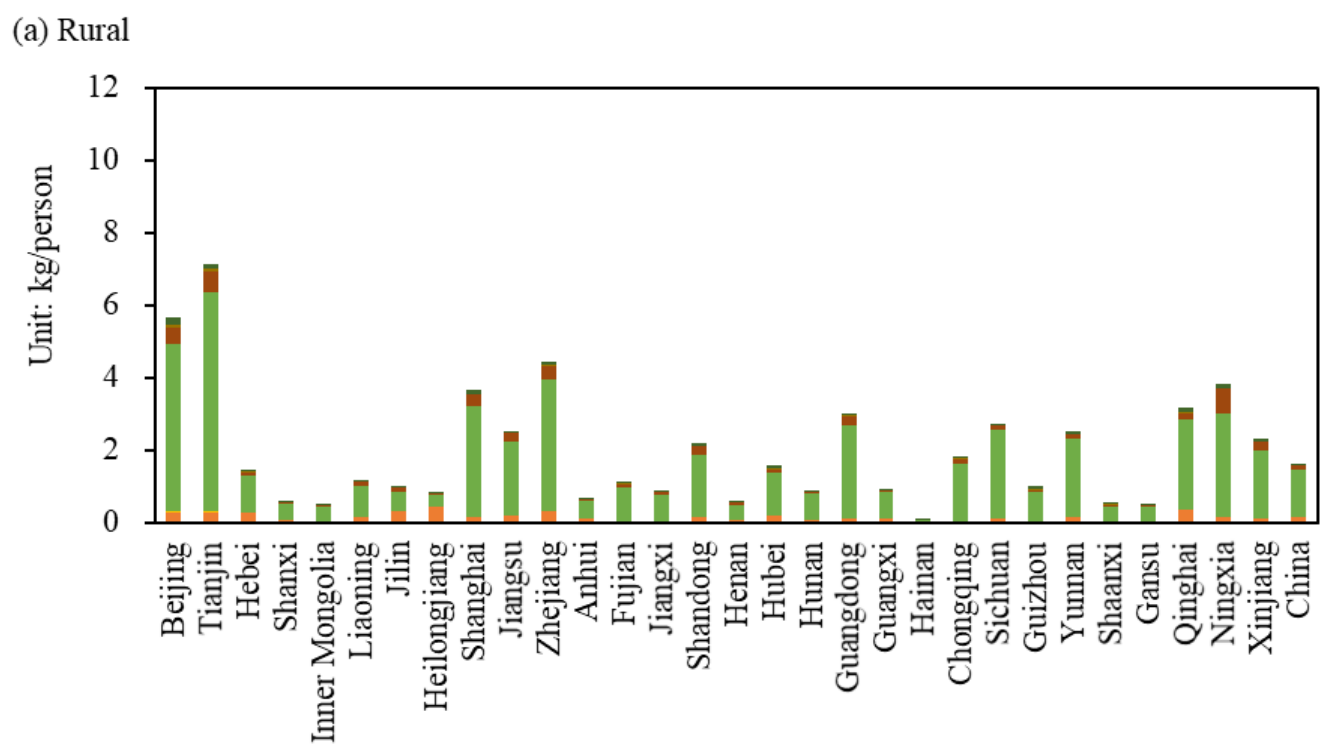

(b) Urban

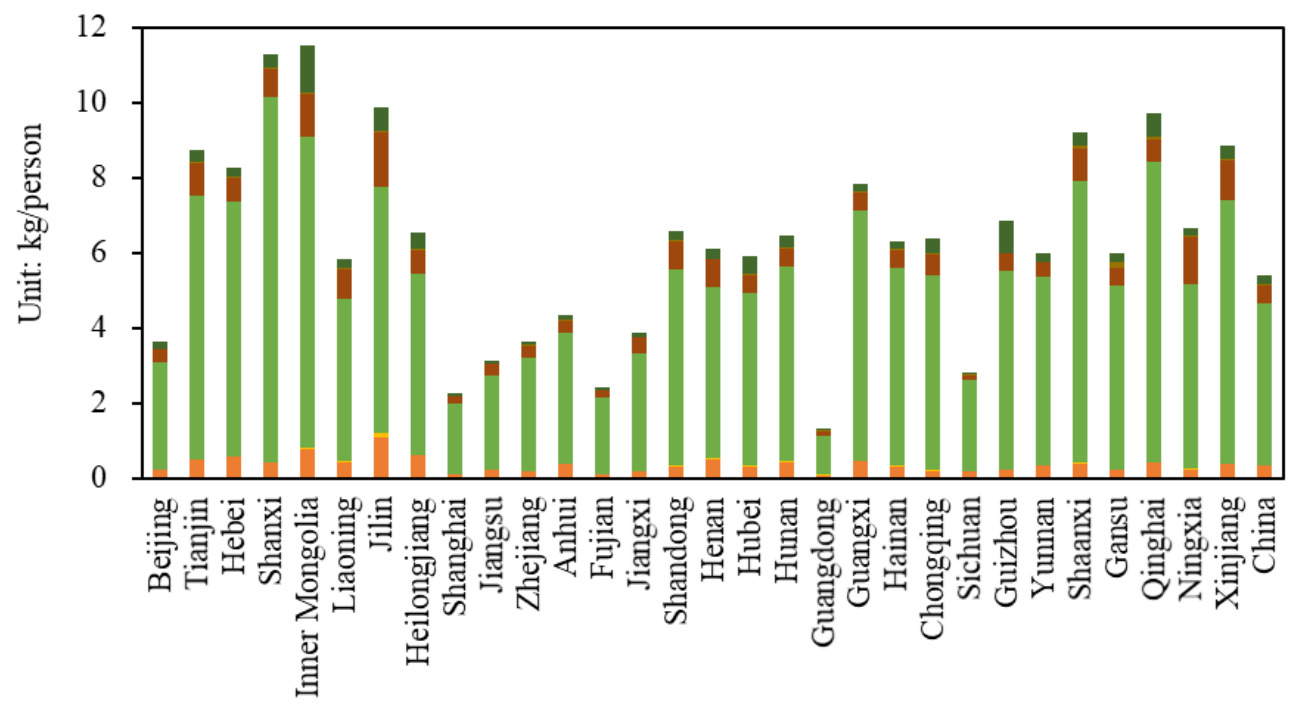

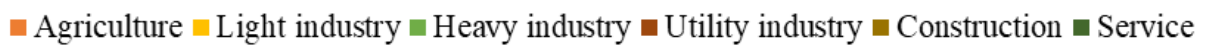

Figure S13. The per-capita indirect emissions of primary $\mathrm{PM}_{2.5}$ embodied in rural (a) and urban (b) investment in 2012. 


\section{S9. Changes in provincial consumption-based $\mathrm{NO}_{x}, \mathrm{SO}_{2}$, primary $\mathrm{PM}_{2.5}$ emissions induced by migration}

We assume a counterfactual scenario for comparison, in which the migration of floating population has not taken place, to evaluate the spatial relocation of air emissions in China. In the real scenario, given that the floating population are required by definition to have lived in places of current residence for more than six months, their emission levels become the same with the local residents with household registration in the present analysis. In the counterfactual scenario, their emission levels are assumed same as those living in their Hukou location. Using the emission data calculated with methods introduced in S3 and S4, and population data obtained from $\mathrm{NBS}^{16}$, we can calculate the per-capita emissions of rural and urban population for each province of China, and further quantify the impacts on air pollutant emissions induced by migration of floating population. Migration-induced emissions are evaluated as a product of population flow and the difference of per-capita emissions between origin and destination. Take an RU migration as an instance. The per-capita emission level in the rural area of province $\mathrm{S}$ is $e_{1}$, and in the urban area, $e_{2}$. If there are $A$ people migrating out of the rural area of province $\mathrm{S}$ and $B$ people immigrating into its urban area from rural area, then the changes in emission $\left(E_{c h a}\right)$ of province $\mathrm{S}$ caused by this process is:

$$
E_{c h a}=B \cdot e_{2}-A \cdot e_{1}
$$

In this research, we assume that migration only affects emissions embodied in household consumption and investment and does not influence the level of government 
consumption, inventory and exports. We calculate the changes of both consumptionand investment-driven emissions for each province resulted from intra- and interprovincial RU migration as well as inter-provincial UU migration, then add up the results to obtain the migration-induced changes of emissions. Since we do not distinguish the emission levels of different cities within the same province, emission changes induced by the intra-provincial UU migration are not included in this study.

Tables $\mathrm{S} 2, \mathrm{~S} 3, \mathrm{~S} 4$ show the changes in consumption-based $\mathrm{NO}_{\mathrm{x}}, \mathrm{SO}_{2}$, primary $\mathrm{PM}_{2.5}$ emissions of each province caused by each type of migration. Table S5, S6, S7 show the sectoral structure of changes in provincial consumption-based $\mathrm{NO}_{\mathrm{x}}, \mathrm{SO}_{2}$, primary $\mathrm{PM}_{2.5}$ emissions. We trace the consumption-based emissions along the supply chain to the most upstream sectors and allocate the emissions to 'producers' (see Section S4), so the emissions from each sector in Tables S5, S6 and S7 refer to the actual pollutants emitted from them to satisfy the final demand. 
Table S2. Changes in provincial consumption-based $\mathrm{NO}_{\mathrm{x}}$ emission caused by each migration pathway (kilo tonne).

\begin{tabular}{|c|c|c|c|c|c|c|c|c|c|c|}
\hline & \multicolumn{3}{|c|}{ Inter-provincial UU } & \multicolumn{3}{|c|}{ Intra-provincial RU } & \multicolumn{3}{|c|}{ Inter-provincial RU } & \multirow{2}{*}{ Sum } \\
\hline & Consumption & Investment & Sum & Consumption & Investment & Sum & Consumption & Investment & Sum & \\
\hline Beijing & 19.6 & 24.4 & 43.9 & 1.4 & -2.4 & -1.0 & 29.7 & 36.7 & 66.3 & 109.3 \\
\hline Tianjin & 4.9 & 15.5 & 20.3 & 0.9 & 1.3 & 2.2 & 12.0 & 37.8 & 49.8 & 72.3 \\
\hline Hebei & -4.2 & -11.3 & -15.6 & 13.4 & 51.1 & 64.5 & -1.3 & 5.6 & 4.3 & 53.2 \\
\hline Shanxi & -1.6 & -5.4 & -7.0 & 5.9 & 54.9 & 60.8 & -0.3 & 7.1 & 6.8 & 60.6 \\
\hline Inner Mongolia & -1.4 & -4.8 & -6.2 & 11.7 & 77.5 & 89.2 & 4.1 & 19.7 & 23.8 & 106.8 \\
\hline Liaoning & -0.1 & -0.4 & -0.5 & 5.6 & 28.4 & 34.0 & 4.7 & 15.4 & 20.1 & 53.6 \\
\hline Jilin & -3.4 & -12.3 & -15.7 & 4.0 & 29.7 & 33.7 & -1.0 & 4.0 & 3.0 & 21.0 \\
\hline Heilongjiang & -7.3 & -16.6 & -23.9 & 5.3 & 24.7 & 30.0 & -3.1 & 1.9 & -1.2 & 4.9 \\
\hline Shanghai & 16.7 & 14.0 & 30.8 & 1.7 & -1.9 & -0.1 & 43.0 & 36.0 & 79.0 & 109.7 \\
\hline Jiangsu & 2.0 & 3.2 & 5.2 & 5.1 & 6.4 & 11.5 & 14.8 & 22.9 & 37.6 & 54.4 \\
\hline Zhejiang & 5.6 & 7.7 & 13.3 & 10.5 & -7.8 & 2.7 & 48.7 & 61.4 & 110.0 & 126.0 \\
\hline Anhui & -7.0 & -15.5 & -22.5 & 7.4 & 28.9 & 36.2 & -14.1 & -6.5 & -20.6 & -6.9 \\
\hline Fujian & 0.5 & 1.3 & 1.8 & 5.2 & 20.3 & 25.5 & 7.1 & 21.4 & 28.5 & 55.8 \\
\hline Jiangxi & -5.3 & -12.2 & -17.5 & 5.0 & 20.5 & 25.5 & -9.1 & -6.4 & -15.5 & -7.5 \\
\hline Shandong & -1.8 & -4.5 & -6.3 & 22.2 & 67.8 & 90.0 & 1.7 & 8.6 & 10.3 & 94.0 \\
\hline Henan & -8.7 & -23.2 & -31.8 & 16.5 & 66.3 & 82.7 & -12.6 & -4.4 & -17.1 & 33.8 \\
\hline Hubei & -6.5 & -16.7 & -23.3 & 9.0 & 39.1 & 48.1 & -8.7 & -5.2 & -13.9 & 10.9 \\
\hline Hunan & -6.5 & -19.1 & -25.6 & 9.7 & 50.0 & 59.6 & -11.9 & -5.5 & -17.4 & 16.6 \\
\hline Guangdong & 23.3 & 18.2 & 41.5 & 26.1 & -40.5 & -14.4 & 91.7 & 69.4 & 161.0 & 188.1 \\
\hline Guangxi & -1.8 & -7.9 & -9.7 & 5.3 & 44.8 & 50.1 & -5.9 & 0.9 & -5.0 & 35.3 \\
\hline Hainan & 0.3 & 1.6 & 1.9 & 0.6 & 8.5 & 9.1 & 0.6 & 4.2 & 4.8 & 15.8 \\
\hline Chongqing & -2.1 & -5.9 & -7.9 & 7.2 & 27.0 & 34.2 & -2.6 & -1.3 & -3.9 & 22.3 \\
\hline Sichuan & -3.5 & -5.6 & -9.1 & 8.8 & 3.3 & 12.1 & -14.1 & -33.9 & -48.0 & -45.0 \\
\hline Guizhou & -2.0 & -5.6 & -7.6 & 7.5 & 32.9 & 40.4 & -4.3 & 1.5 & -2.7 & 30.1 \\
\hline
\end{tabular}


Table S2 Continued.

\begin{tabular}{|c|c|c|c|c|c|c|c|c|c|c|}
\hline & \multicolumn{3}{|c|}{ Inter-provincial UU } & \multicolumn{3}{|c|}{ Intra-provincial RU } & \multicolumn{3}{|c|}{ Inter-provincial RU } & \multirow{2}{*}{ Sum } \\
\hline & Consumption & Investment & Sum & Consumption & Investment & Sum & Consumption & Investment & Sum & \\
\hline Yunnan & 0.6 & 1.9 & 2.4 & 5.2 & 21.0 & 26.1 & 1.0 & 5.0 & 6.0 & 34.6 \\
\hline Shaanxi & -0.8 & -3.0 & -3.7 & 7.8 & 53.8 & 61.5 & 0.0 & 11.3 & 11.3 & 69.1 \\
\hline Gansu & -1.1 & -2.7 & -3.8 & 4.4 & 20.0 & 24.4 & -1.6 & 2.1 & 0.5 & 21.0 \\
\hline Qinghai & -0.3 & -1.0 & -1.3 & 1.1 & 7.4 & 8.5 & 1.0 & 4.8 & 5.8 & 13.1 \\
\hline Ningxia & -0.1 & -0.1 & -0.2 & 1.9 & 4.1 & 6.1 & 1.2 & 2.9 & 4.2 & 10.0 \\
\hline Xinjiang & 1.3 & 3.8 & 5.1 & 4.9 & 16.7 & 21.6 & 8.3 & 24.9 & 33.2 & 59.8 \\
\hline China & 9.4 & -82.3 & -73.0 & 221.2 & 753.6 & 974.7 & 178.8 & 342.1 & 520.8 & 1422.6 \\
\hline
\end{tabular}

Table S3. Changes in provincial consumption-based $\mathrm{SO}_{2}$ emission caused by each migration pathway (kilo tonne).

\begin{tabular}{|c|c|c|c|c|c|c|c|c|c|c|}
\hline & \multicolumn{3}{|c|}{ Inter-provincial UU } & \multicolumn{3}{|c|}{ Intra-provincial RU } & \multicolumn{3}{|c|}{ Inter-provincial RU } & \multirow{2}{*}{ Sum } \\
\hline & Consumption & Investment & Sum & Consumption & Investment & Sum & Consumption & Investment & Sum & \\
\hline Beijing & 14.1 & 20.4 & 34.5 & -0.4 & -2.1 & -2.6 & 21.2 & 30.8 & 52.0 & 83.9 \\
\hline Tianjin & 3.1 & 12.9 & 16.0 & 0.2 & 1.1 & 1.3 & 7.5 & 31.5 & 39.0 & 56.3 \\
\hline Hebei & -3.4 & -9.5 & -12.9 & 8.0 & 43.4 & 51.4 & -2.8 & 5.1 & 2.3 & 40.8 \\
\hline Shanxi & -1.9 & -6.0 & -7.9 & 1.7 & 60.6 & 62.3 & -1.7 & 7.9 & 6.2 & 60.6 \\
\hline Inner Mongolia & -1.9 & -5.0 & -6.9 & 14.8 & 82.1 & 96.8 & 5.3 & 20.8 & 26.1 & 116.0 \\
\hline Liaoning & -0.1 & -0.3 & -0.4 & 4.8 & 26.1 & 30.9 & 3.4 & 14.1 & 17.5 & 48.0 \\
\hline Jilin & -2.1 & -9.0 & -11.1 & 3.3 & 21.9 & 25.2 & -0.2 & 3.1 & 2.8 & 16.9 \\
\hline Heilongjiang & -3.9 & -13.1 & -17.0 & 3.4 & 19.9 & 23.3 & -1.2 & 1.8 & 0.5 & 6.9 \\
\hline Shanghai & 12.3 & 14.4 & 26.7 & 1.2 & -2.3 & -1.2 & 31.6 & 36.9 & 68.5 & 94.1 \\
\hline Jiangsu & 1.5 & 3.4 & 4.9 & 4.1 & 6.1 & 10.2 & 11.5 & 23.9 & 35.3 & 50.4 \\
\hline Zhejiang & 4.7 & 7.3 & 12.0 & 8.3 & -8.5 & -0.1 & 40.6 & 57.9 & 98.5 & 110.4 \\
\hline
\end{tabular}


Table S3 continued.

\begin{tabular}{|c|c|c|c|c|c|c|c|c|c|c|}
\hline & \multicolumn{3}{|c|}{ Inter-provincial UU } & \multicolumn{3}{|c|}{ Intra-provincial RU } & \multicolumn{3}{|c|}{ Inter-provincial RU } & \multirow{2}{*}{ Sum } \\
\hline & Consumption & Investment & Sum & Consumption & Investment & Sum & Consumption & Investment & Sum & \\
\hline Anhui & -4.6 & -13.6 & -18.2 & 5.5 & 25.7 & 31.1 & -7.9 & -5.0 & -12.9 & 0.1 \\
\hline Fujian & 0.3 & 1.0 & 1.3 & 3.3 & 14.9 & 18.2 & 4.6 & 15.4 & 20.0 & 39.5 \\
\hline Jiangxi & -4.0 & -10.7 & -14.7 & 3.8 & 18.5 & 22.3 & -7.0 & -4.7 & -11.7 & -4.1 \\
\hline Shandong & -1.7 & -4.7 & -6.5 & 20.1 & 73.9 & 94.0 & 1.5 & 9.7 & 11.1 & 98.7 \\
\hline Henan & -6.7 & -23.9 & -30.6 & 9.0 & 69.1 & 78.1 & -14.8 & -3.7 & -18.5 & 28.9 \\
\hline Hubei & -9.0 & -23.2 & -32.3 & 14.2 & 56.5 & 70.8 & -10.0 & -4.8 & -14.8 & 23.7 \\
\hline Hunan & -7.0 & -20.8 & -27.8 & 8.0 & 54.7 & 62.7 & -16.4 & -5.5 & -21.9 & 13.0 \\
\hline Guangdong & 19.8 & 15.4 & 35.3 & 25.8 & -33.5 & -7.7 & 78.3 & 58.9 & 137.2 & 164.8 \\
\hline Guangxi & -2.3 & -9.1 & -11.4 & 9.4 & 52.0 & 61.4 & -4.1 & 1.5 & -2.6 & 47.4 \\
\hline Hainan & 0.3 & 1.6 & 1.9 & 0.8 & 8.9 & 9.7 & 0.6 & 4.5 & 5.0 & 16.7 \\
\hline Chongqing & -3.4 & -9.6 & -13.0 & 5.0 & 45.4 & 50.4 & -11.1 & -1.0 & -12.1 & 25.2 \\
\hline Sichuan & -5.4 & -11.5 & -16.9 & 8.5 & 20.8 & 29.3 & -26.9 & -55.2 & -82.1 & -69.7 \\
\hline Guizhou & -5.6 & -8.5 & -14.1 & 14.8 & 49.3 & 64.1 & -20.0 & 2.0 & -18.0 & 32.0 \\
\hline Yunnan & 0.8 & 2.3 & 3.1 & 5.4 & 27.2 & 32.6 & 0.7 & 6.7 & 7.4 & 43.2 \\
\hline Shaanxi & -0.8 & -3.0 & -3.8 & 5.5 & 54.3 & 59.9 & -1.4 & 11.5 & 10.1 & 66.1 \\
\hline Gansu & -0.9 & -2.6 & -3.5 & 2.5 & 18.9 & 21.4 & -2.3 & 2.0 & -0.3 & 17.6 \\
\hline Qinghai & -0.2 & -0.8 & -1.0 & 0.4 & 5.8 & 6.2 & 0.7 & 3.7 & 4.4 & 9.6 \\
\hline Ningxia & -0.1 & -0.1 & -0.2 & 1.0 & 4.1 & 5.1 & 0.9 & 2.8 & 3.7 & 8.6 \\
\hline Xinjiang & 1.0 & 3.5 & 4.4 & 2.9 & 15.5 & 18.4 & 6.1 & 22.7 & 28.8 & 51.7 \\
\hline China & -7.2 & -102.9 & -110.1 & 195.5 & 830.2 & 1025.7 & 86.7 & 295.0 & 381.7 & 1297.3 \\
\hline
\end{tabular}


Table S4. Changes in provincial consumption-based primary $\mathrm{PM}_{2.5}$ emission caused by each migration pathway (kilo tonne).

\begin{tabular}{|c|c|c|c|c|c|c|c|c|c|c|}
\hline & \multicolumn{3}{|c|}{ Inter-provincial UU } & \multicolumn{3}{|c|}{ Intra-provincial RU } & \multicolumn{3}{|c|}{ Inter-provincial RU } & \multirow{2}{*}{ Sum } \\
\hline & Consumption & Investment & Sum & Consumption & Investment & Sum & Consumption & Investment & Sum & \\
\hline Beijing & 5.7 & 8.3 & 14.1 & -1.8 & -1.0 & -2.8 & 8.5 & 12.6 & 21.1 & 32.4 \\
\hline Tianjin & 1.3 & 5.4 & 6.8 & -0.2 & 0.3 & 0.1 & 3.2 & 13.3 & 16.5 & 23.4 \\
\hline Hebei & -1.4 & -4.7 & -6.1 & -6.1 & 20.9 & 14.8 & -6.8 & 2.2 & -4.6 & 4.2 \\
\hline Shanxi & -0.8 & -2.7 & -3.5 & -4.3 & 27.0 & 22.7 & -1.9 & 3.5 & 1.6 & 20.8 \\
\hline Inner Mongolia & -0.7 & -1.7 & -2.4 & -13.8 & 27.5 & 13.7 & -1.1 & 7.0 & 5.9 & 17.1 \\
\hline Liaoning & 0.0 & -0.1 & -0.2 & -10.4 & 8.4 & -2.0 & -0.7 & 4.6 & 4.0 & 1.8 \\
\hline Jilin & -1.2 & -4.1 & -5.3 & -8.9 & 9.6 & 0.7 & -5.6 & 1.2 & -4.4 & -8.9 \\
\hline Heilongjiang & -2.9 & -6.1 & -9.0 & -9.8 & 8.6 & -1.1 & -9.6 & 0.4 & -9.2 & -19.3 \\
\hline Shanghai & 6.4 & 4.8 & 11.3 & 0.6 & -0.7 & -0.1 & 16.5 & 12.4 & 28.9 & 40.1 \\
\hline Jiangsu & 0.7 & 1.2 & 1.9 & -5.6 & 2.1 & -3.4 & 2.0 & 8.4 & 10.4 & 8.9 \\
\hline Zhejiang & 1.5 & 2.8 & 4.3 & 0.1 & -3.1 & -3.0 & 12.7 & 22.0 & 34.7 & 36.0 \\
\hline Anhui & -3.0 & -6.0 & -9.0 & -7.4 & 11.0 & 3.6 & -27.3 & -2.8 & -30.1 & -35.5 \\
\hline Fujian & 0.1 & 0.3 & 0.5 & -8.4 & 4.9 & -3.6 & -0.8 & 5.2 & 4.4 & 1.3 \\
\hline Jiangxi & -1.6 & -4.0 & -5.7 & -5.6 & 6.7 & 1.0 & -14.6 & -2.3 & -16.9 & -21.6 \\
\hline Shandong & -0.6 & -1.5 & -2.1 & -5.6 & 22.8 & 17.2 & -3.5 & 2.9 & -0.6 & 14.4 \\
\hline Henan & -3.1 & -8.0 & -11.1 & -2.4 & 22.9 & 20.5 & -15.3 & -1.5 & -16.9 & -7.4 \\
\hline Hubei & -2.2 & -6.2 & -8.4 & -11.6 & 14.1 & 2.5 & -18.5 & -2.4 & -20.8 & -26.8 \\
\hline Hunan & -3.2 & -7.7 & -10.9 & -5.2 & 20.1 & 14.9 & -19.5 & -2.4 & -21.9 & -17.8 \\
\hline Guangdong & 6.9 & 5.1 & 12.1 & -3.4 & -13.3 & -16.6 & 26.9 & 19.4 & 46.4 & 41.8 \\
\hline Guangxi & -0.8 & -3.3 & -4.1 & -10.3 & 18.6 & 8.3 & -17.5 & 0.2 & -17.4 & -13.3 \\
\hline Hainan & 0.1 & 0.6 & 0.7 & -2.8 & 3.1 & 0.3 & -0.6 & 1.6 & 1.0 & 1.9 \\
\hline Chongqing & -0.7 & -2.1 & -2.8 & -6.5 & 9.6 & 3.1 & -9.5 & -0.6 & -10.1 & -9.8 \\
\hline Sichuan & -1.2 & -2.1 & -3.4 & -20.3 & 0.4 & -19.9 & -29.0 & -13.8 & -42.8 & -66.1 \\
\hline Guizhou & -0.9 & -2.0 & -2.9 & -4.4 & 11.6 & 7.2 & -11.0 & 0.2 & -10.7 & -6.4 \\
\hline
\end{tabular}


Table $\mathbf{S 4}$ continued.

\begin{tabular}{|c|c|c|c|c|c|c|c|c|c|c|}
\hline & \multicolumn{3}{|c|}{ Inter-provincial UU } & \multicolumn{3}{|c|}{ Intra-provincial RU } & \multicolumn{3}{|c|}{ Inter-provincial RU } & \multirow{2}{*}{ Sum } \\
\hline & Consumption & Investment & Sum & Consumption & Investment & Sum & Consumption & Investment & Sum & \\
\hline Yunnan & 0.2 & 0.7 & 0.9 & -4.6 & 7.7 & 3.1 & -2.1 & 1.8 & -0.4 & 3.6 \\
\hline Shaanxi & -0.2 & -1.1 & -1.3 & -5.9 & 19.6 & 13.7 & -3.9 & 4.1 & 0.2 & 12.6 \\
\hline Gansu & -0.4 & -1.0 & -1.3 & -3.2 & 7.1 & 3.9 & -3.8 & 0.7 & -3.1 & -0.5 \\
\hline Qinghai & -0.1 & -0.3 & -0.4 & -0.7 & 2.3 & 1.6 & 0.1 & 1.5 & 1.6 & 2.8 \\
\hline Ningxia & 0.0 & 0.0 & -0.1 & -1.4 & 1.3 & -0.2 & 0.0 & 0.9 & 0.9 & 0.7 \\
\hline Xinjiang & 0.4 & 1.2 & 1.7 & -0.5 & 5.3 & 4.8 & 2.6 & 8.0 & 10.6 & 17.0 \\
\hline China & -1.5 & -34.3 & -35.8 & -170.6 & 275.4 & 104.9 & -130.1 & 108.3 & -21.7 & 47.3 \\
\hline
\end{tabular}

Table S5. The sectoral structure of changes in provincial consumption-based $\mathrm{NO}_{\mathrm{x}}$ emission (kilo tonne).

\begin{tabular}{|c|c|c|c|c|c|c|c|c|}
\hline & Agriculture & Light industry & Heavy industry & Utility industry & Construction & Service & Household & Sum \\
\hline Beijing & 7.9 & 1.3 & 31.2 & 37.6 & 0.8 & 28.1 & 2.4 & 109.3 \\
\hline Tianjin & 4.1 & 0.4 & 26.4 & 28.3 & 0.7 & 12.0 & 0.5 & 72.3 \\
\hline Hebei & 2.1 & 0.1 & 22.4 & 20.8 & 0.6 & 9.8 & -2.5 & 53.2 \\
\hline Shanxi & 2.6 & 0.2 & 29.5 & 18.2 & 0.5 & 11.5 & -1.9 & 60.6 \\
\hline Inner Mongolia & 4.4 & 0.3 & 37.9 & 46.6 & 0.8 & 16.4 & 0.3 & 106.8 \\
\hline Liaoning & 2.8 & 0.3 & 17.0 & 22.6 & 0.4 & 12.8 & -2.3 & 53.6 \\
\hline Jilin & 0.3 & 0.4 & 8.2 & 9.2 & 0.2 & 5.2 & -2.5 & 21.0 \\
\hline Heilongjiang & -0.9 & -0.1 & 4.3 & 3.4 & 0.1 & 1.8 & -3.7 & 4.9 \\
\hline Shanghai & 14.1 & 1.2 & 32.3 & 37.8 & 0.4 & 22.7 & 1.2 & 109.7 \\
\hline Jiangsu & 3.2 & 0.3 & 17.4 & 19.5 & 0.3 & 14.0 & -0.4 & 54.4 \\
\hline Zhejiang & 8.8 & 0.9 & 39.4 & 47.9 & 1.0 & 27.7 & 0.2 & 126.0 \\
\hline Anhui & -2.3 & 0.0 & 0.6 & 0.7 & 0.1 & -0.3 & -5.7 & -6.9 \\
\hline Fujian & 1.9 & 0.3 & 28.6 & 15.6 & 0.5 & 10.5 & -1.7 & 55.8 \\
\hline
\end{tabular}


Table S5 continued.

\begin{tabular}{|c|c|c|c|c|c|c|c|c|}
\hline & Agriculture & Light industry & Heavy industry & Utility industry & Construction & Service & Household & Sum \\
\hline Jiangxi & -1.4 & 0.0 & -1.2 & -0.6 & 0.0 & -0.4 & -3.8 & -7.5 \\
\hline Shandong & 6.9 & 0.7 & 29.3 & 40.3 & 0.6 & 17.8 & -1.6 & 94.0 \\
\hline Henan & 0.0 & 0.1 & 12.1 & 17.3 & 0.1 & 8.8 & -4.6 & 33.8 \\
\hline Hubei & -1.2 & -0.1 & 9.1 & 5.8 & 0.1 & 3.1 & -5.8 & 10.9 \\
\hline Hunan & -0.3 & 0.1 & 10.2 & 6.3 & 0.3 & 5.0 & -4.9 & 16.6 \\
\hline Guangdong & 13.9 & 1.9 & 51.8 & 67.3 & 0.2 & 51.4 & 1.6 & 188.1 \\
\hline Guangxi & 0.7 & 0.3 & 19.8 & 10.9 & 0.3 & 8.2 & -4.8 & 35.3 \\
\hline Hainan & 0.7 & 0.1 & 7.3 & 5.0 & 0.1 & 3.0 & -0.5 & 15.8 \\
\hline Chongqing & 0.8 & 0.1 & 9.4 & 9.7 & 0.1 & 5.9 & -3.8 & 22.3 \\
\hline Sichuan & -0.4 & 0.0 & -29.1 & -2.8 & -0.7 & -2.6 & -9.4 & -45.0 \\
\hline Guizhou & 0.0 & 0.1 & 11.4 & 11.2 & 0.1 & 10.9 & -3.7 & 30.1 \\
\hline Yunnan & 1.5 & 0.2 & 14.5 & 10.4 & 0.2 & 9.4 & -1.6 & 34.6 \\
\hline Shaanxi & 2.5 & 0.3 & 29.3 & 25.9 & 0.3 & 12.5 & -1.8 & 69.1 \\
\hline Gansu & 0.6 & 0.1 & 8.8 & 7.7 & 0.4 & 4.9 & -1.4 & 21.0 \\
\hline Qinghai & 0.5 & 0.1 & 4.3 & 3.5 & 1.1 & 3.8 & -0.2 & 13.1 \\
\hline Ningxia & 1.1 & 0.1 & 3.1 & 4.3 & 0.0 & 1.8 & -0.4 & 10.0 \\
\hline Xinjiang & 2.4 & 0.4 & 20.7 & 24.8 & 0.1 & 11.1 & 0.2 & 59.8 \\
\hline China & 77.2 & 10.2 & 506.2 & 555.4 & 9.7 & 326.5 & -62.6 & 1422.6 \\
\hline
\end{tabular}


Table S6. The sectoral structure of changes in provincial consumption-based $\mathrm{SO}_{2}$ emission (kilo tonne).

\begin{tabular}{|c|c|c|c|c|c|c|c|c|}
\hline & Agriculture & Light industry & Heavy industry & Utility industry & Construction & Service & Household & Sum \\
\hline Beijing & 1.0 & 2.2 & 43.8 & 29.3 & 0.2 & 8.0 & -0.6 & 83.9 \\
\hline Tianjin & 0.5 & 0.6 & 31.4 & 20.0 & 0.2 & 3.7 & -0.3 & 56.3 \\
\hline Hebei & 0.3 & 0.2 & 27.7 & 14.1 & 0.2 & 3.2 & -4.9 & 40.8 \\
\hline Shanxi & 0.3 & 0.3 & 45.5 & 16.3 & 0.1 & 5.7 & -7.6 & 60.6 \\
\hline Inner Mongolia & 0.6 & 0.6 & 56.1 & 35.2 & 0.2 & 17.0 & 6.3 & 116.0 \\
\hline Liaoning & 0.4 & 0.4 & 27.9 & 16.8 & 0.1 & 2.5 & -0.1 & 48.0 \\
\hline Jilin & 0.0 & 0.4 & 10.1 & 5.3 & 0.0 & 1.4 & -0.3 & 16.9 \\
\hline Heilongjiang & -0.1 & 0.0 & 5.4 & 2.2 & 0.0 & 0.4 & -0.9 & 6.9 \\
\hline Shanghai & 1.9 & 2.1 & 52.5 & 30.1 & 0.1 & 6.2 & 1.2 & 94.1 \\
\hline Jiangsu & 0.5 & 0.6 & 30.5 & 16.8 & 0.1 & 2.2 & -0.2 & 50.4 \\
\hline Zhejiang & 1.4 & 2.0 & 55.1 & 47.2 & 0.3 & 4.8 & -0.3 & 110.4 \\
\hline Anhui & -0.3 & -0.1 & 2.0 & 0.6 & 0.0 & 0.0 & -2.1 & 0.1 \\
\hline Fujian & 0.3 & 0.8 & 26.4 & 12.0 & 0.1 & 1.6 & -1.7 & 39.5 \\
\hline Jiangxi & -0.2 & -0.1 & 0.2 & -0.6 & 0.0 & -0.1 & -3.3 & -4.1 \\
\hline Shandong & 0.8 & 2.2 & 49.4 & 38.7 & 0.1 & 8.7 & -1.3 & 98.7 \\
\hline Henan & 0.0 & 0.2 & 24.6 & 15.2 & 0.0 & 2.3 & -13.4 & 28.9 \\
\hline Hubei & -0.2 & -0.1 & 21.0 & 4.5 & 0.0 & 4.5 & -6.1 & 23.7 \\
\hline Hunan & -0.1 & 0.2 & 16.9 & 6.0 & 0.1 & 2.4 & -12.5 & 13.0 \\
\hline Guangdong & 2.2 & 4.0 & 86.6 & 62.2 & 0.1 & 8.6 & 1.1 & 164.8 \\
\hline Guangxi & 0.1 & 0.9 & 30.3 & 13.7 & 0.1 & 2.7 & -0.4 & 47.4 \\
\hline Hainan & 0.1 & 0.2 & 9.9 & 5.6 & 0.0 & 1.0 & -0.1 & 16.7 \\
\hline Chongqing & 0.1 & 0.6 & 23.1 & 14.6 & 0.0 & 7.8 & -21.0 & 25.2 \\
\hline Sichuan & -0.1 & 0.0 & -37.3 & -7.5 & -0.2 & -0.1 & -24.5 & -69.7 \\
\hline Guizhou & 0.0 & 0.5 & 26.3 & 15.1 & 0.0 & 15.2 & -25.1 & 32.0 \\
\hline Yunnan & 0.2 & 0.5 & 29.9 & 13.6 & 0.0 & 4.4 & -5.5 & 43.2 \\
\hline
\end{tabular}


Table S6 continued.

\begin{tabular}{|c|c|c|c|c|c|c|c|c|}
\hline & Agriculture & Light industry & Heavy industry & Utility industry & Construction & Service & Household & Sum \\
\hline Shaanxi & 0.3 & 0.7 & 39.1 & 24.9 & 0.2 & 5.7 & -4.8 & 66.1 \\
\hline Gansu & 0.1 & 0.2 & 13.1 & 6.4 & 0.2 & 1.2 & -3.6 & 17.6 \\
\hline Qinghai & 0.0 & 0.1 & 6.7 & 2.4 & 0.0 & 1.0 & -0.6 & 9.6 \\
\hline Ningxia & 0.1 & 0.2 & 4.4 & 4.4 & 0.0 & 0.6 & -1.1 & 8.6 \\
\hline Xinjiang & 0.3 & 0.8 & 29.2 & 17.9 & 0.1 & 3.6 & -0.2 & 51.7 \\
\hline China & 10.8 & 21.2 & 787.8 & 483.1 & 2.4 & 126.2 & -134.1 & 1297.3 \\
\hline
\end{tabular}

Table S7. The sectoral structure of changes in provincial consumption-based primary $\mathrm{PM}_{2.5}$ emission (kilo tonne).

\begin{tabular}{|c|c|c|c|c|c|c|c|c|}
\hline & Agriculture & Light industry & Heavy industry & Utility industry & Construction & Service & Household & Sum \\
\hline Beijing & 6.9 & 0.4 & 20.7 & 3.7 & 0.1 & 2.0 & -1.4 & 32.4 \\
\hline Tianjin & 3.4 & 0.1 & 16.5 & 2.8 & 0.1 & 0.9 & -0.5 & 23.4 \\
\hline Hebei & 1.5 & 0.0 & 16.7 & 1.9 & 0.1 & 0.8 & -16.9 & 4.2 \\
\hline Shanxi & 2.0 & 0.1 & 24.7 & 2.0 & 0.1 & 1.4 & -9.5 & 20.8 \\
\hline Inner Mongolia & 4.2 & 0.1 & 24.5 & 3.8 & 0.2 & 4.2 & -19.8 & 17.1 \\
\hline Liaoning & 2.8 & 0.1 & 10.5 & 2.3 & 0.1 & 0.7 & -14.8 & 1.8 \\
\hline Jilin & 0.3 & 0.1 & 4.8 & 1.3 & 0.0 & 0.5 & -16.0 & -8.9 \\
\hline Heilongjiang & -1.2 & 0.0 & 2.7 & 0.4 & 0.0 & 0.2 & -21.5 & -19.3 \\
\hline Shanghai & 14.7 & 0.3 & 19.8 & 3.4 & 0.1 & 1.4 & 0.4 & 40.1 \\
\hline Jiangsu & 4.0 & 0.1 & 12.5 & 2.0 & 0.1 & 0.5 & -10.4 & 8.9 \\
\hline Zhejiang & 8.7 & 0.2 & 24.8 & 4.7 & 0.2 & 1.1 & -3.7 & 36.0 \\
\hline Anhui & -2.3 & 0.0 & 0.6 & 0.1 & 0.0 & 0.0 & -33.8 & -35.5 \\
\hline Fujian & 2.1 & 0.1 & 10.1 & 1.4 & 0.1 & 0.4 & -12.9 & 1.3 \\
\hline Jiangxi & -1.0 & 0.0 & -0.5 & -0.1 & 0.0 & 0.0 & -20.0 & -21.6 \\
\hline
\end{tabular}


Table S7 continued.

\begin{tabular}{|c|c|c|c|c|c|c|c|c|}
\hline & Agriculture & Light industry & Heavy industry & Utility industry & Construction & Service & Household & Sum \\
\hline Shandong & 4.7 & 0.2 & 20.6 & 3.8 & 0.1 & 1.6 & -16.6 & 14.4 \\
\hline Henan & 0.1 & 0.0 & 10.1 & 1.8 & 0.0 & 0.6 & -20.0 & -7.4 \\
\hline Hubei & -0.9 & 0.0 & 4.6 & 0.6 & 0.0 & 0.8 & -32.0 & -26.8 \\
\hline Hunan & -0.5 & 0.0 & 6.4 & 0.7 & 0.1 & 0.5 & -25.1 & -17.8 \\
\hline Guangdong & 17.4 & 0.5 & 25.9 & 6.4 & 0.0 & 1.9 & -10.3 & 41.8 \\
\hline Guangxi & 0.9 & 0.1 & 13.7 & 1.1 & 0.1 & 0.5 & -29.6 & -13.3 \\
\hline Hainan & 0.8 & 0.0 & 4.5 & 0.5 & 0.0 & 0.2 & -4.1 & 1.9 \\
\hline Chongqing & 0.8 & 0.0 & 5.8 & 0.9 & 0.0 & 0.9 & -18.4 & -9.8 \\
\hline Sichuan & -0.4 & 0.0 & -14.8 & -0.3 & -0.2 & -0.1 & -50.3 & -66.1 \\
\hline Guizhou & 0.1 & 0.0 & 7.7 & 0.9 & 0.0 & 2.2 & -17.4 & -6.4 \\
\hline Yunnan & 1.4 & 0.1 & 9.6 & 1.0 & 0.0 & 0.8 & -9.2 & 3.6 \\
\hline Shaanxi & 2.2 & 0.1 & 19.1 & 2.5 & 0.2 & 1.1 & -12.6 & 12.6 \\
\hline Gansu & 0.5 & 0.0 & 5.6 & 0.7 & 0.2 & 0.3 & -7.9 & -0.5 \\
\hline Qinghai & 0.3 & 0.0 & 3.3 & 0.3 & 0.0 & 0.3 & -1.4 & 2.8 \\
\hline Ningxia & 0.8 & 0.0 & 1.9 & 0.6 & 0.0 & 0.2 & -2.8 & 0.7 \\
\hline Xinjiang & 3.0 & 0.1 & 12.4 & 2.6 & 0.1 & 0.8 & -2.0 & 17.0 \\
\hline China & 77.4 & 2.8 & 324.9 & 53.8 & 2.1 & 26.7 & -440.4 & 47.3 \\
\hline
\end{tabular}




\section{S10. Uncertainty analysis}

\section{S10.1 Influences of Hukou migration}

As mentioned in the main text and Section S2, we adopt the data of floating population, which is obtained from official national census, to depict the amount and direction of population migration in China. Apart from floating population (defined as individuals living in places other than their household registration areas for at least six months $s^{3,4}$ ), there are also some migrants who directly change their household registration and move to another residence place. Such migrants, referred to as Hukou migration in the following section, may also have some influences on the air pollutant emissions. Since this research only investigates the influences of RU and UU migration, which directly increase urban population in the urbanization process, the following contents will focus on the Hukou migration with urban area as destination.

Different from floating population, there are no statistics directly focused on Hukou migration. We estimated such migration based on the data of non-agricultural population in cities by region (which is defined as urban population in the Hukou system) and natural growth rate of population by region obtained from China Population and Employment Statistics Yearbook ${ }^{22,23}$. The total growth of urban Hukou population $\left(G_{\text {total }}\right)$ of each province in 2012 is calculated with equation (5):

$$
G_{\text {total }}=P_{2012}-P_{2011}
$$

,where $P_{2012}$ is the urban Hukou population in 2012. 
The natural growth of urban Hukou population $\left(G_{\text {natural }}\right)$ of each province in 2012 is calculated with equation (6):

$$
G_{\text {natural }}=P_{2011} \cdot G R_{2012}
$$

, where $P_{2011}$ is the urban Hukou population at the end of $2011 ; G R_{2012}$ refers to the natural growth rate of population in 2012 .

The change in urban Hukou population of each province resulted from population migration ( $G_{\text {migration }}$, Hukou migration) in 2012 can be estimated with equation (7):

$$
G_{\text {migration }}=G_{\text {total }}-G_{\text {natural }}
$$

Figure S14 shows the proportion of Hukou migration to floating population migrating into the urban area of each province/municipality in 2012. On national level, the amount of Hukou migration is 4.2 million, which is only $2.8 \%$ of the amount of floating population, indicating that floating population is the dominant population migration in China. Most provinces/municipalities share the similar feature with the national case that Hukou migration has small contribution to the change in urban resident population, except for Jilin, Jiangsu, Chongqing, Sichuan and Yunnan (see Figure S14). Most of these five provinces witnessed a net outflow of population in 2012 (see Figure S3), and the Hukou limitation was relatively loose. Besides, the public spending required to support a newly registered urban resident is relative low in these central and southwestern provinces, which further promote the citizenization of migrants $^{24}$. In Jilin province, there are 1.5 million floating population (including both 
the RU ones and inter-provincial UU ones) migrating into the urban area, while 0.3 million urban registered residents change there Hukou and migrate out. Such Hukou emigration, attributable to the downward trend of economy ${ }^{25}$, decreases the urban immigrants by $22.1 \%$. In contrast, in Yunnan provinces there are 3.2 million floating population migrating into urban area, and as a result, Hukou migration increases urban immigrants by $32.2 \%$.

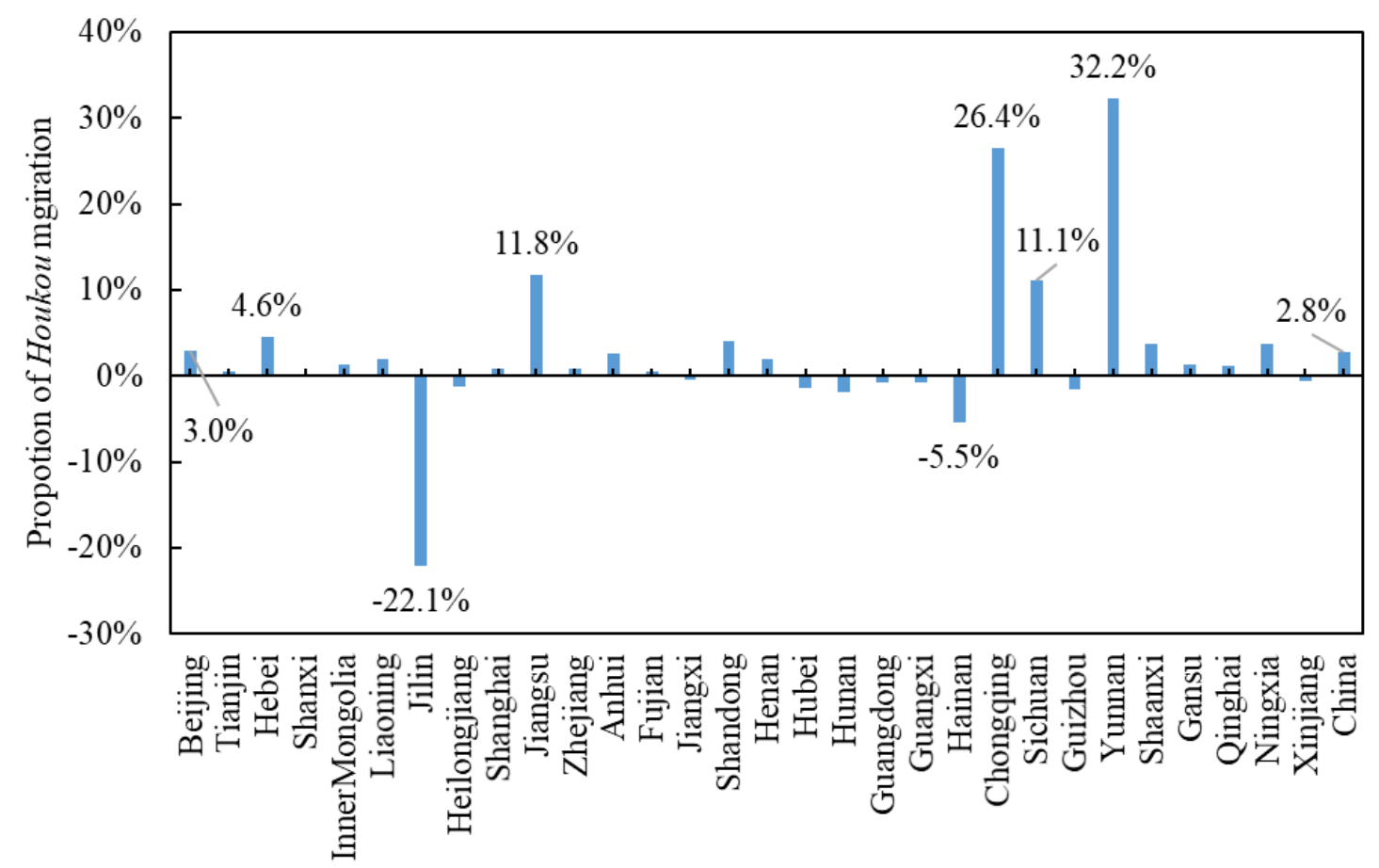

Figure S14. The proportion of Hukou migration to floating population who migrate into the urban area of each province/municipality in 2012. The negative value means the urban registered residents change their Hukou and migrate to other places.

We assumed that Hukou migration has the same source structure as the migration of floating population, and constructed the RU and UU migration matrices with Hukou migration taken into consideration. The influences of Hukou migration on air pollutant emissions are estimated with the method introduced in Section S9. Table S8 and S9 
show the air pollutant emissions induced by Hukou migration, and the proportions to the original results based only on floating population. The air pollutants induced by floating population migration are $1.42 \mathrm{Mt}$ for $\mathrm{NO}_{\mathrm{x}}, 1.30 \mathrm{Mt}$ for $\mathrm{SO}_{2}$ and $0.05 \mathrm{Mt}$ for primary $\mathrm{PM}_{2.5}$ (see Section 3 in the main text). In contrast, the air pollutants induced by Hukou migration are much lower than those induced by floating population, which are merely $32.3 \mathrm{kt}$ for $\mathrm{NO}_{\mathrm{x}}, 43.1 \mathrm{kt}$ for $\mathrm{SO}_{2}$ and $0.7 \mathrm{kt}$ for primary $\mathrm{PM}_{2.5}$. With Hukou migration taken into consideration, the $\mathrm{NO}_{\mathrm{x}}, \mathrm{SO}_{2}$ and primary $\mathrm{PM}_{2.5}$ emissions induced by population migration will increased by $2.3 \%, 3.3 \%$, and $1.6 \%$ respectively, compared to the original results.

We assumed that the changes of urban registered residents are caused by either natural growth, or migration within China. However, there are also some other possibilities. First, newly registered urban residents may come from abroad, which is beyond the scope of provincial migration in this research (https://news.qq.com/cross/20151210/1Kk0I0x7.html, in Chinese). Second, the change of Hukou type may be caused by the change of administrative division and land use (i.e. from township to sub-district), which is referred to as in-situ urbanization ${ }^{26}$. In this case, a rural registered resident may become an urban registered one without migration, and his/her lifestyle and emission level may not change that rapidly. Thus, the results here could be taken as the upper limit of the influences induced by Hukou migration. 
Table S8. The influences of each migration path on air pollutant emissions induced by Hukou migration and the proportion to the original results based on floating population. There are three migration paths: inter-provincial urban to urban (Inter-UU), inter-provincial rural to urban (Inter-RU) and intra-provincial rural to urban (Intra-RU). Cons refers to the emissions related to household consumption, and inve refers to those related to investment.

\begin{tabular}{|c|c|c|c|c|c|c|}
\hline & \multicolumn{2}{|c|}{$\mathrm{NO}_{\mathrm{x}}$} & \multicolumn{2}{|c|}{$\mathrm{SO}_{2}$} & \multicolumn{2}{|c|}{ Primary $\mathrm{PM}_{2.5}$} \\
\hline & Amount (kt) & Proportion (\%) & Amount (kt) & Proportion (\%) & Amount (kt) & Proportion (\%) \\
\hline Inter-UU cons & -0.2 & $-2.3 \%$ & 0.0 & $-0.6 \%$ & -0.2 & $12.4 \%$ \\
\hline Inter-UU inve & -1.8 & $2.1 \%$ & -0.4 & $0.4 \%$ & -0.6 & $1.7 \%$ \\
\hline Inter-RU cons & 2.9 & $1.6 \%$ & 1.9 & $2.2 \%$ & -2.7 & $2.1 \%$ \\
\hline Inter-RU inve & 8.5 & $2.5 \%$ & 10.3 & $3.5 \%$ & 3.1 & $2.9 \%$ \\
\hline Intra-RU cons & 6.3 & $2.9 \%$ & 4.9 & $2.5 \%$ & -4.9 & $2.9 \%$ \\
\hline Total & 32.3 & $2.3 \%$ & 43.1 & $3.3 \%$ & 0.7 & $1.6 \%$ \\
\hline
\end{tabular}

Table S9. The emissions from each source category induced by Hukou migration and the proportion to the original results based on floating population.

\begin{tabular}{|c|c|c|c|c|c|c|}
\hline & \multicolumn{2}{|c|}{$\mathrm{NO}_{\mathrm{x}}$} & \multicolumn{2}{|c|}{$\mathrm{SO}_{2}$} & \multicolumn{2}{|c|}{ Primary $\mathrm{PM}_{2.5}$} \\
\hline & Amount (kt) & Proportion (\%) & Amount (kt) & Proportion (\%) & Amount (kt) & Proportion (\%) \\
\hline Agriculture & 1.9 & $2.5 \%$ & 0.3 & $2.5 \%$ & 1.7 & $2.2 \%$ \\
\hline Heavy industry & 11.9 & $2.3 \%$ & 28.4 & $3.6 \%$ & 8.7 & $2.7 \%$ \\
\hline Utility industry & 12.0 & $2.2 \%$ & 16.7 & $3.5 \%$ & 0.9 & $1.7 \%$ \\
\hline Construction & 0.1 & $1.3 \%$ & 0.0 & $1.6 \%$ & 0.0 & $1.4 \%$ \\
\hline Service & 8.2 & $2.5 \%$ & 4.6 & $3.6 \%$ & 0.6 & $2.2 \%$ \\
\hline Household & -1.8 & $2.8 \%$ & -7.5 & $5.6 \%$ & -11.2 & $2.5 \%$ \\
\hline Total & 32.3 & $2.3 \%$ & 43.1 & $3.3 \%$ & 0.7 & $1.6 \%$ \\
\hline
\end{tabular}




\section{S10.2 Monte Carlo simulation}

The overall uncertainty of the results was quantified through Monte Carlo simulation. The uncertainties mainly come from four categories of data: the emission inventory, the direct requirement coefficient matrix derived from the MRIO table (matrix $A$, see also Section $\mathrm{S} 4$ ), the rural and urban investment ratio, as well as the migration data. The uncertainty ranges (represented as either the $95 \%$ confidence interval, CI, or the upper and lower limit) of each data category are discussed below.

Following the evaluation on the uncertainties of China's emission inventory reported by Zhao et al. ${ }^{27}$, we obtain the $95 \% \mathrm{CI}$ for the emissions of $\mathrm{NO}_{\mathrm{x}}, \mathrm{SO}_{2}$ and primary $\mathrm{PM}_{2.5}$ from each industrial source category, as is shown in Table S10. The emissions of $\mathrm{NO}_{\mathrm{x}}, \mathrm{SO}_{2}$ and primary $\mathrm{PM}_{2.5}$ obtained from the Tsinghua emission inventory were assumed to follow normal distributions. We assume that the emissions of agriculture, service and residential sectors have the same uncertainty level as that of the total industrial emission (the row of Total in Table S10) reported by Zhao et al.

Each element of matrix $A$ was assumed also to follow a normal distribution with a $95 \%$ CI of $[-10 \%, 10 \%]$ (relative to the value obtained from the MRIO table), following the practice of Lin et al. ${ }^{28}$ and Zhao et al. ${ }^{29}$ In addition, we assume the rural and urban investment ratios following the uniform distribution. The data in Table S1 (see Section S5) are taken as the central estimate, with variation range set as $[-5 \%, 5 \%]$.

As to the migration data, we also assume them following uniform distribution. The lower limit of the uniform distribution is the migration matrix based only on floating 
population, and the upper limit is the matrix taken both floating population and Hukou migration into consideration (see Section S10.1 for more information).

Table S10. The $95 \%$ CI for emissions of $\mathrm{NO}_{\mathrm{x}}, \mathrm{SO}_{2}$ and the primary $\mathrm{PM}_{2.5}$ from each industrial source category (represented as the percentage around the central estimate).

\begin{tabular}{cccc}
\hline & $\mathrm{NO}_{\mathrm{x}}$ & $\mathrm{SO}_{2}$ & Primary $_{2.5}$ \\
\hline Power plant & {$[-28 \%, 28 \%]$} & {$[-71 \%, 71 \%]$} & {$[-60 \%, 60 \%]$} \\
Cement & {$[-74 \%, 74 \%]$} & {$[-55 \%, 55 \%]$} & {$[-197 \%, 197 \%]$} \\
Steel & {$[-57 \%, 57 \%]$} & {$[-90 \%, 90 \%]$} & {$[-63 \%, 63 \%]$} \\
Other industrial process & {$[-43 \%, 43 \%]$} & {$[-36 \%, 36 \%]$} & {$[-55 \%, 55 \%]$} \\
Other industrial combustion & {$[-151 \%, 151 \%]$} & {$[-59 \%, 59 \%]$} & {$[-256 \%, 256 \%]$} \\
Total & {$[-35 \%, 35 \%]$} & {$[-37 \%, 37 \%]$} & {$[-54 \%, 54 \%]$} \\
\hline
\end{tabular}

With consideration of the uncertainty ranges of different data mentioned above, we evaluated the overall uncertainty of the results using Monte Carlo approach with 500,000 simulations for each of the three air pollutants with results presented in Figure S15. The estimated $\mathrm{NO}_{\mathrm{x}}$ emission induced by population migration is $1.42 \mathrm{Mt}$ (see Section 3 in the main text), and its $95 \% \mathrm{CI}$ is $[1.35,1.52] \mathrm{Mt}$, or $[-5.14 \%, 6.86 \%]$ around the central estimate. The $\mathrm{SO}_{2}$ emission induced by population migration is $1.30 \mathrm{Mt}$, with the $95 \% \mathrm{CI}$ of $[1.21,1.42] \mathrm{Mt}$, or $[-6.66 \%, 9.21 \%]$. The primary $\mathrm{PM}_{2.5}$ emission induced by population migration is $0.05 \mathrm{Mt}$, with a $95 \% \mathrm{CI}$ of $[-0.03,0.12] \mathrm{Mt}$, or [$160.62 \%, 156.12 \%]$. The relative uncertainty of primary $\mathrm{PM}_{2.5}$ (measured by percentage around the central estimate) is much larger than that of $\mathrm{NO}_{\mathrm{x}}$ and $\mathrm{SO}_{2}$, reflecting the fact that the central value for primary $\mathrm{PM}_{2.5}$ is close to zero and the large uncertainty associated with its emission inventory (see Table S10). 

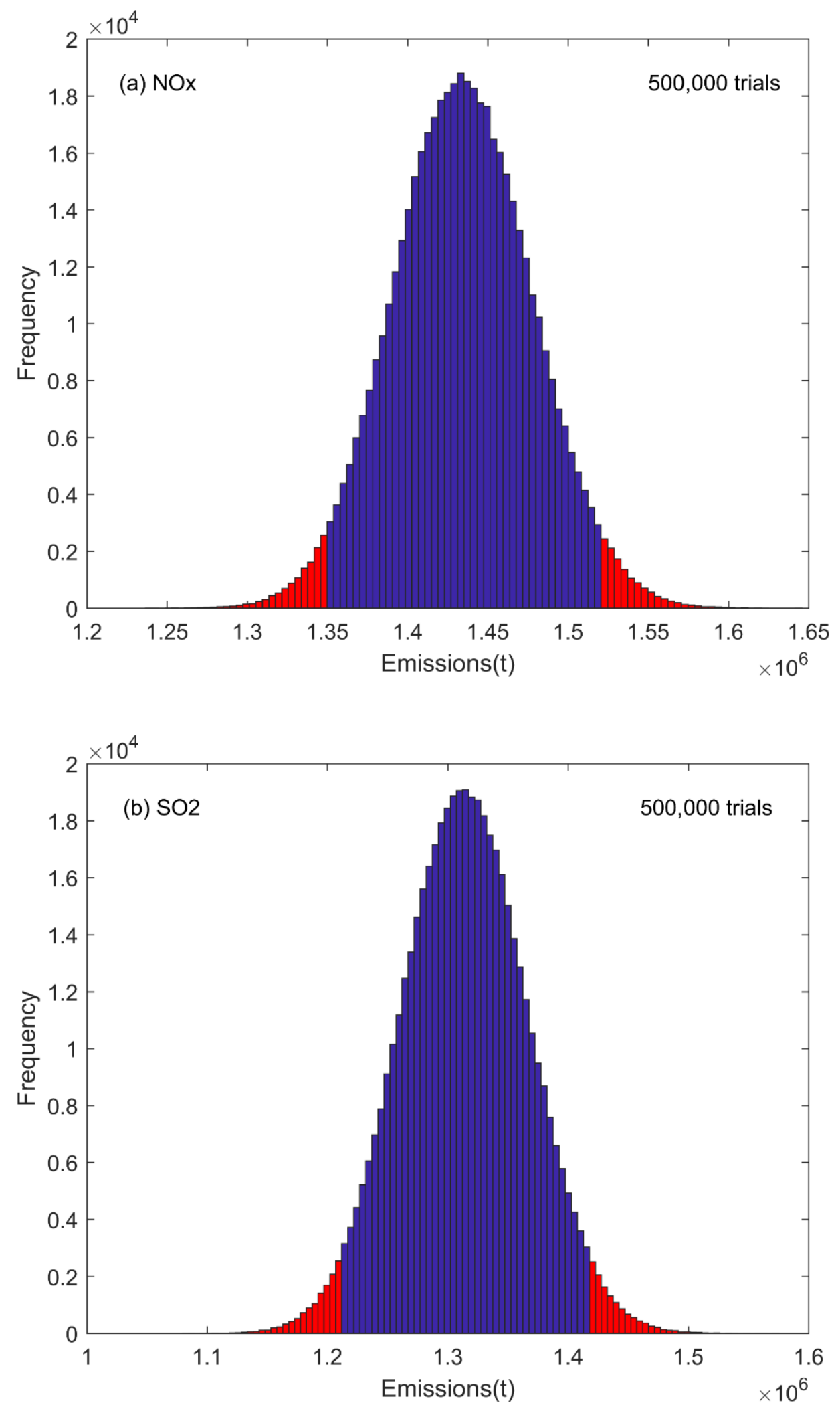


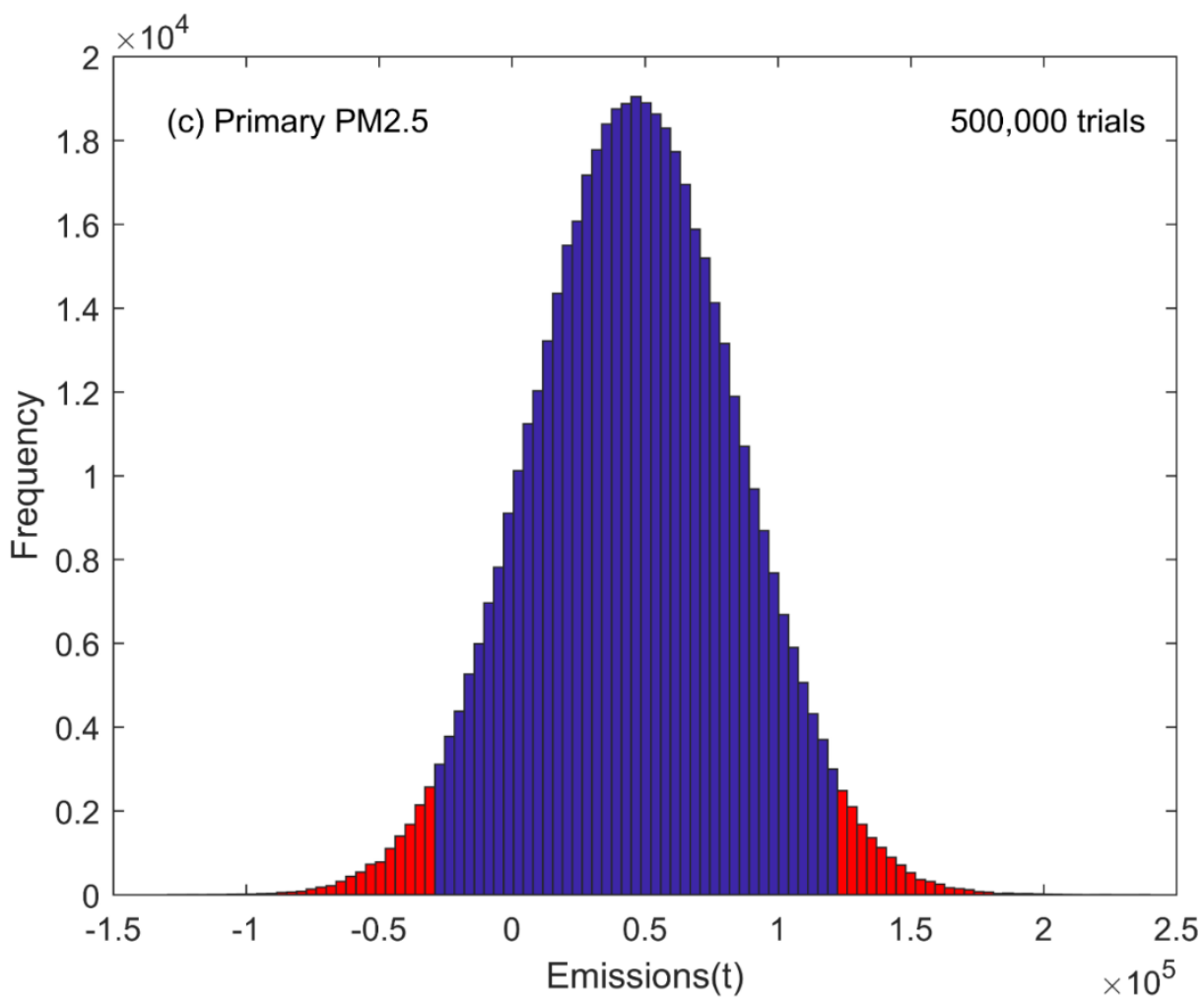

Figure S15. The Monte Carlo simulation results for the $\mathrm{NO}_{\mathrm{x}}(\mathrm{a}), \mathrm{SO}_{2}$ (b) and primary $\mathrm{PM}_{2.5}$ (c) emissions induced by population migration. 500,000 trials are done for each kind of air pollutants. The blue bars represent the results within the $95 \%$ confidential interval (CI), and red bars represent those beyond the $95 \% \mathrm{CI}$. 


\section{References}

(1) Cai, S. Y.; Wang, Y. J.; Zhao, B.; Wang, S. X.; Chang, X.; Hao, J. M. The impact of the "Air Pollution Prevention and Control Action Plan" on $\mathrm{PM}_{2.5}$ concentrations in Jing-Jin-Ji region during 2012-2020. Sci. Total Environ. 2017, 580, 197-209.

(2) Wang, S. X.; Zhao, B.; Cai, S. Y.; Klimont, Z.; Nielsen, C. P.; Morikawa, T.; Woo, J. H.; Kim, Y.; Fu, X.; Xu, J. Y.; Hao, J. M.; He, K. B. Emission trends and mitigation options for air pollutants in East Asia. Atmos. Chem. Phys. 2014, 14 (13), 6571-6603.

(3) Ai, T. H.; Zhou, M. J.; Tian, J.; Ye, N. Origin-destination (OD) of the interprovincial floating population of China. J. Maps 2016, 12 (sup1), 577-583.

(4) National Bureau of Statistics. Population and employment, 2018. http://www.stats.gov.cn/tjzs/cjwtjd/201308/t20130829_74322.html (accessed Aug 28, 2018). In Chinese. (5) National Bureau of Statistics. Tabulation on the 2010 Population Census of the People's Republic of China; China Statistics Press: Beijing, 2012. In Chinese..

(6) National Bureau of Statistics. 1\% National Population Sample Survey Data 2015; China Statistics Press: Beijing, 2016. In Chinese.

(7) Mi, Z. F.; Meng, J.; Zheng, H. R.; Shan, Y. L.; Wei, Y.-M.; Guan, D. B. A multi-regional input-output table mapping China's economic outputs and interdependencies in 2012. Sci. Data 2018, 5, 180155.

(8) Shan, Y. L.; Guan, D. B.; Zheng, H. R.; Ou, J. M.; Li, Y.; Meng, J.; Mi, Z. F.; Liu, Z.; Zhang, Q. China $\mathrm{CO}_{2}$ emission accounts 1997-2015. Sci. Data 2018, 5, 170201.

(9) China Emission Accounts and Datasets (CEADs). Energy Inventory. http://www.ceads.net/data/energyinventory/ (accessed Mar 10, 2018)

(10) National Bureau of Statistics. China Energy Statistical Yearbook; China Statistics Press: Beijing, 2017. In Chinese.

(11) China Automobile Dealers Association. China's Auto Market Almanac; China Business Press: Beijing, 2013. In Chinese.

(12) Liu, Y.; Meng, B.; Hubacek, K.; Xue, J. J.; Feng, K. S.; Gao, Y. N. 'Made in China': A reevaluation of embodied $\mathrm{CO}_{2}$ emissions in Chinese exports using firm heterogeneity information. Appl. Energy 2016, $184,1106-1113$.

(13) Peters, G. P. From production-based to consumption-based national emission inventories. Ecolog. 
Econ. 2008, 65(1), 13-23.

(14) National Bureau of Statistics. Statistical Yearbook of the Chinese Investment in Fixed Assets; China Statistics Press: Beijing, 2010. In Chinese.

(15) National Bureau of Statistics. Statistical Yearbook of the Chinese Investment in Fixed Assets; China Statistics Press: Beijing, 2011. In Chinese.

(16) National Bureau of Statistics. China Statistical Yearbook; China Statistics Press: Beijing, 2017. In Chinese.

(17) Duan, P. P.; Wang, W. F.; Liu, X. H.; Qian, F. C.; Sang, S. X.; Xu, S. C. Distribution of As, Hg and other trace elements in different size and density fractions of the Reshuihe high-sulfur coal, Yunnan Province, China. Int. J. Coal Geol. 2017, 173, 129-141.

(18) Zhao, Y. Y.; Zeng, F. G.; Liang, H. Z.; Tang, Y. G.; Li, M. F.; Xiang, J. H.; Wen, X. T. Chromium and vanadium bearing nanominerals and ultra-fine particles in a super-high-organic-sulfur coal from Ganhe coalmine, Yanshan Coalfield, Yunnan, China. Fuel 2017, 203, 832-842.

(19) Shen, G. F. Changes from traditional solid fuels to clean household energies - Opportunities in emission reduction of primary $\mathrm{PM}_{2.5}$ from residential cookstoves in China. Biomass Bioenergy 2016, 86 , 28-35.

(20) Li, M.; Liu, H.; Geng, G. N.; Hong, C. P.; Liu, F.; Song, Y.; Tong, D.; Zheng, B.; Cui, H. Y.; Man, H. Y.; Zhang, Q.; He, K. B. Anthropogenic emission inventories in China: a review. Natl. Sci. Rev. 2017, 4 (6), 834-866.

(21) Shi, Z. H.; Li, J. Y.; Huang, L.; Wang, P.; Wu, L.; Ying, Q.; Zhang, H. L.; Lu, L.; Liu, X. J.; Liao, H.; Hu, J. L. Source apportionment of fine particulate matter in China in 2013 using a source-oriented chemical transport model. Sci. Total Environ. 2017, 601-602, 1476-1487.

(22) National Bureau of Statistics. China Population and Employment Statistics Yearbook; China Statistics Press: Beijing, 2012. In Chinese.

(23) National Bureau of Statistics. China Population and Employment Statistics Yearbook; China Statistics Press: Beijing, 2013. In Chinese.

(24) Liu, R.; Cao, G. Z. Population size, distribution and factors impacting on citizenization of Chinese migrant workers. Prog. Geogr. 2014, 33(6), 748-755. In Chinese.

(25) Wei, H. K. The new predicament of economic development in Northeastern China and its revitalization strategy. Soc. Sci. J. 2017, (1), 26-32. In Chinese. 
(26) Zhou, T.; Jiang, G. H.; Zhang, R. J.; Zheng, Q. Y.; Ma, W. Q.; Zhao, Q. L.; Li, Y. L. Addressing the rural in situ urbanization (RISU) in the Beijing-Tianjin-Hebei region: Spatio-temporal pattern and driving mechanism. Cities 2018, 75, 59-71.

(27) Zhao, Y.; Zhou, Y. D.; Qiu, L. P.; Zhang, J. Quantifying the uncertainties of China's emission inventory for industrial sources: From national to provincial and city scales. Atmos. Environ. 2017, 165, 207-221.

(28) Lin, J. T.; Pan, D.; Davis, S. J.; Zhang, Q.; He, K. B.; Wang, C.; Streets, D. G.; Wuebbles, D. J.; Guan, D. B. China's international trade and air pollution in the United States. Proc. Natl. Acad. Sci. USA 2014, $111(5), 1734-1741$.

(29) Zhao, H. Y.; Geng, G. N.; Zhang, Q.; Davis, S. J.; Li, X.; Liu, Y.; Peng, L. Q.; Li, M.; Zheng, B.; Huo, H.; Zhang, L.; Henze, D. K.; Mi. Z. F.; Liu, Z.; Guan, D. B.; He, K. B. Inequality of household consumption and air pollution-related deaths in China. Nat. Commun. 2019, 10 (1), 4337. 